OPEN ACCESS

Edited by:

Alessandra Stasi,

University of Bari Aldo Moro, Italy

Reviewed by:

Charles E. McCall,

Wake Forest Baptist Medical Center,

United States

Lixin Xie,

People 's Liberation Army General

Hospital, China

*Correspondence:

Yan-fen Chai

chaiyanfen2012@126.com

Yu-lei Gao

gaoyulei828@126.com

Specialty section: This article was submitted to Inflammation,

a section of the journal

Frontiers in Immunology

Received: 05 December 2021 Accepted: 07 February 2022 Published: 25 February 2022

Citation:

Gao Y-I, Yao Y, Zhang X, Chen F, Meng X-I, Chen X-s, Wang C-I, Liu Y-C,

Tian X, Shou S-t and Chai Y-f (2022)

Regulatory T Cells: Angels or Demons

in the Pathophysiology of Sepsis?

Front. Immunol. 13:829210.

doi: 10.3389/fimmu.2022.829210

\section{Regulatory T Cells: Angels or Demons in the Pathophysiology of Sepsis?}

\author{
Yu-lei Gao ${ }^{1 *}$, Ying Yao ${ }^{1}$, Xiang Zhang ${ }^{2}$, Fang Chen ${ }^{1}$, Xiang-long Meng ${ }^{1}$, Xin-sen Chen ${ }^{1}$, \\ Chao-lan Wang ${ }^{1}$, Yan-cun Liu ${ }^{1}$, Xin Tian ${ }^{3}$, Song-tao Shou ${ }^{1}$ and Yan-fen Chai ${ }^{1 *}$ \\ ${ }^{1}$ Department of Emergency Medicine, Tianjin Medical University General Hospital, Tianjin, China, ${ }^{2}$ Department of Emergency \\ Medicine, Rizhao People's Hospital of Shandong Province, Rizhao, China, ${ }^{3}$ Department of Medical Research, Beijing \\ Qiansong Technology Development Company, Beijing, China
}

Sepsis is a syndrome characterized by life-threatening organ dysfunction caused by the dysregulated host response to an infection. Sepsis, especially septic shock and multiple organ dysfunction is a medical emergency associated with high morbidity, high mortality, and prolonged after-effects. Over the past 20 years, regulatory T cells (Tregs) have been a key topic of focus in all stages of sepsis research. Tregs play a controversial role in sepsis based on their heterogeneous characteristics, complex organ/tissue-specific patterns in the host, the multi-dimensional heterogeneous syndrome of sepsis, the different types of pathogenic microbiology, and even different types of laboratory research models and clinical research methods. In the context of sepsis, Tregs may be considered both angels and demons. We propose that the symptoms and signs of sepsis can be attenuated by regulating Tregs. This review summarizes the controversial roles and Treg checkpoints in sepsis.

Keywords: sepsis, regulatory T cells, pathophysiology, checkpoints, secondary infections

\section{INTRODUCTION}

A study of the global burden of disease from 1990 to 2017 showed that an estimated 48.9 million (38.9-62.9) sepsis cases were recorded globally and 11.0 million (10.1-12.0) sepsis-related deaths were reported in 2017, representing 19.7\% (18.2-21.4) of global deaths (1). In China, one-fifth of patients admitted to intensive care units (ICU) have sepsis and their 90-day mortality rate is $35.5 \%$. It is estimated that the annual medical costs of the 230,000 septic patients admitted to China's ICUs are about US $\$ 4.6$ billion, which is a huge medical and social burden (2). In 2015, over 1.9 million deaths occurred in 605 disease-surveillance points in mainland China, and the standardized sepsisrelated mortality incidence was 66.7 deaths per 100,000 population (3). Despite the $37 \%$ (11.8-54.5) decrease in age-standardized sepsis and the 58\% (47.7-57.5) decrease in mortality from 1990 to 2017, aggressive infection source control, early appropriate antibiotic treatment, titration, compression therapy, and improved organ support measures, sepsis remains one of the major causes of global mortality (1-7).

Regulatory $\mathrm{T}$ cells (Tregs) are a subset of $\mathrm{CD} 4+\mathrm{T}$ lymphocytes with negative immunomodulatory functions. They maintain peripheral immune tolerance to control immune responses to prevent exaggerated responses to infections and harmless antigens, and prevent autoimmunity. Due to the extensive regulatory role that Tregs play in the immune system, they have considerable potential as treatment for various diseases $(8-10)$. The discovery that forkhead box P3 
(Foxp3) is a key transcription factor in the differentiation and function of Tregs has multiple implications for understanding how the immune system functions and for developing therapeutic interventions for autoimmune diseases, infectious diseases, and malignancies (11-13).

Over the past two decades, Tregs have been a focus in sepsisinduced immune-inflammatory dysfunction research and the hotspot strategy in immunotherapy and checkpoint inhibition $(14,15)$. In sepsis, reduced $\mathrm{T}$ cell function is associated with increased expression of Foxp3 (16-18). CD4+ T helper 17 cells (Th17) represent the pro-inflammatory subpopulation, while Tregs promote anti-inflammatory effects (19-22). This review explores the current controversial, and sometimes conflicting, conclusions about Tregs in the pathophysiology of sepsis. Both laboratory and clinical research methods and models need to be considered to begin to understand the precise role of Tregs throughout the stages of sepsis (Figure 1).

\section{SEPSIS}

Research on the epidemiology, prevention, and management of sepsis is an important topic for critical care medicine, surgery, and anesthesiology, where clarification of the complex pathophysiological mechanism of sepsis is a fundamental problem $(14,23,24)$. Since 1992, the definitions of sepsis, severe sepsis, and septic shock, as well as associated clinical and laboratory studies have relied on the presence of infection and the characteristics of systemic inflammatory response syndrome (SIRS) (1, 24-28). However, efforts to inhibit this hyper-inflammatory response syndrome by blocking proinflammatory cytokines, such as interleukin (IL)-1 $\beta$ and tumor necrosis factor (TNF)- $\alpha$, ultimately fail to yield survival benefits $(26,27)$. Physicians have emphasized the evaluation of sepsisinduced organ dysfunction when they conduct the diagnosis and treatment of sepsis, especially based on the sequential (sepsisrelated) organ failure assessment (SOFA), national early warning score and modified early warning score, rather than quick SOFA (qSOFA) (4-6, 24, 28-32).

Antagonism between the host and pathogenic microorganisms is a complex pathophysiological reaction: pathogens seek an advantage by incapacitating various aspects of host defenses while the host seeks to control the bacterial invasion and initiate repair of injured tissues $(33,34)$ (Figure 2). Compared with Sepsis 3.0 criteria, the definition of Sepsis 2.0 and 1.0, as well as guidelines for the diagnosis and treatment of sepsis, focus more on pathophysiological mechanisms $(4,25,26,29,35)$. The first three days of sepsis are defined as the early stage; in these cases, more than $80 \%$ of patients first seek emergency medicine according to their clinical manifestations of the biological systemic immune-inflammatory response $(26,36-$ 43). As sepsis management techniques continue to improve,
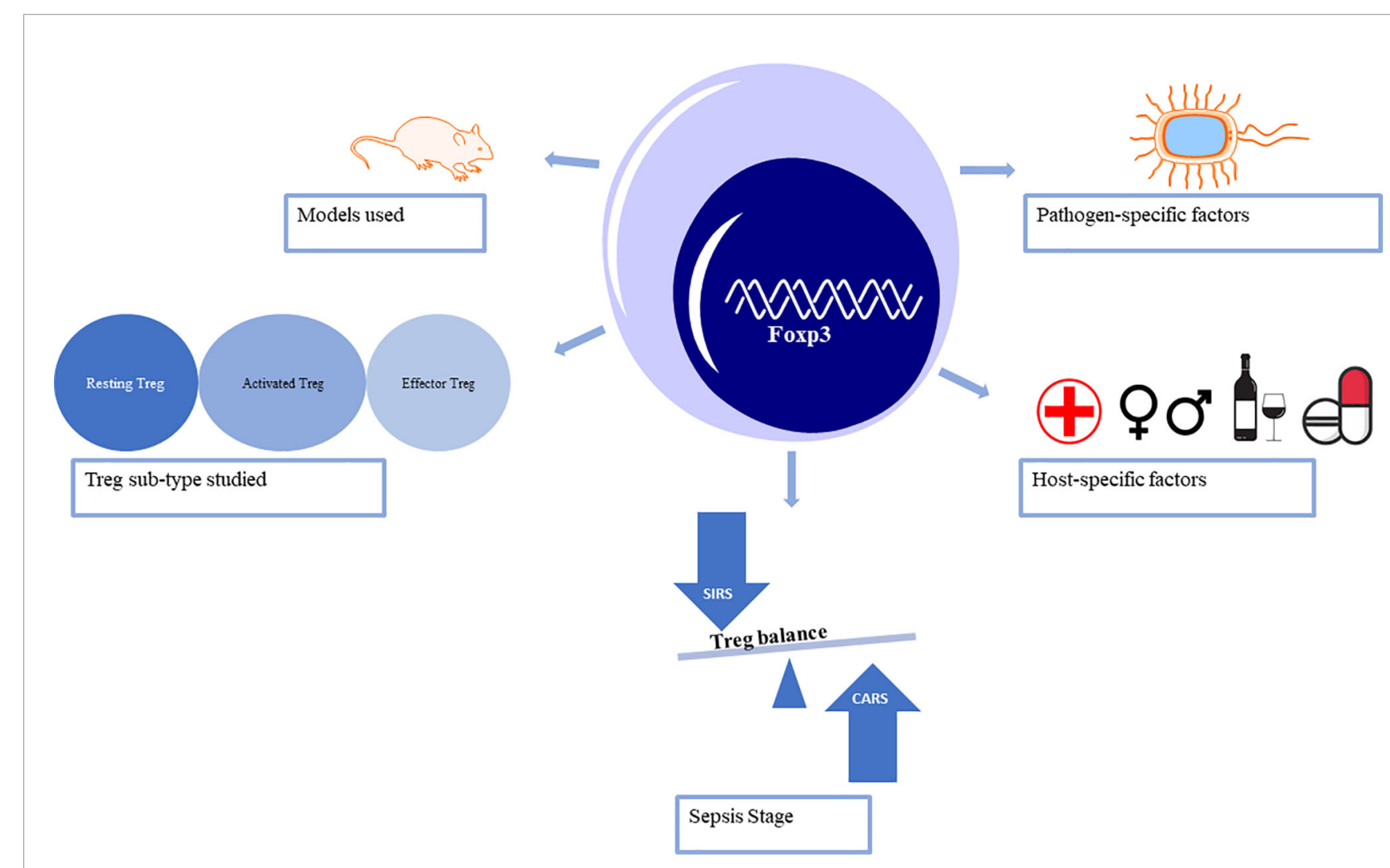

Pathogen-specific factors

FIGURE 1 | Factors that lead to the controversy surrounding the role of regulatory $\top$ cells in sepsis. 


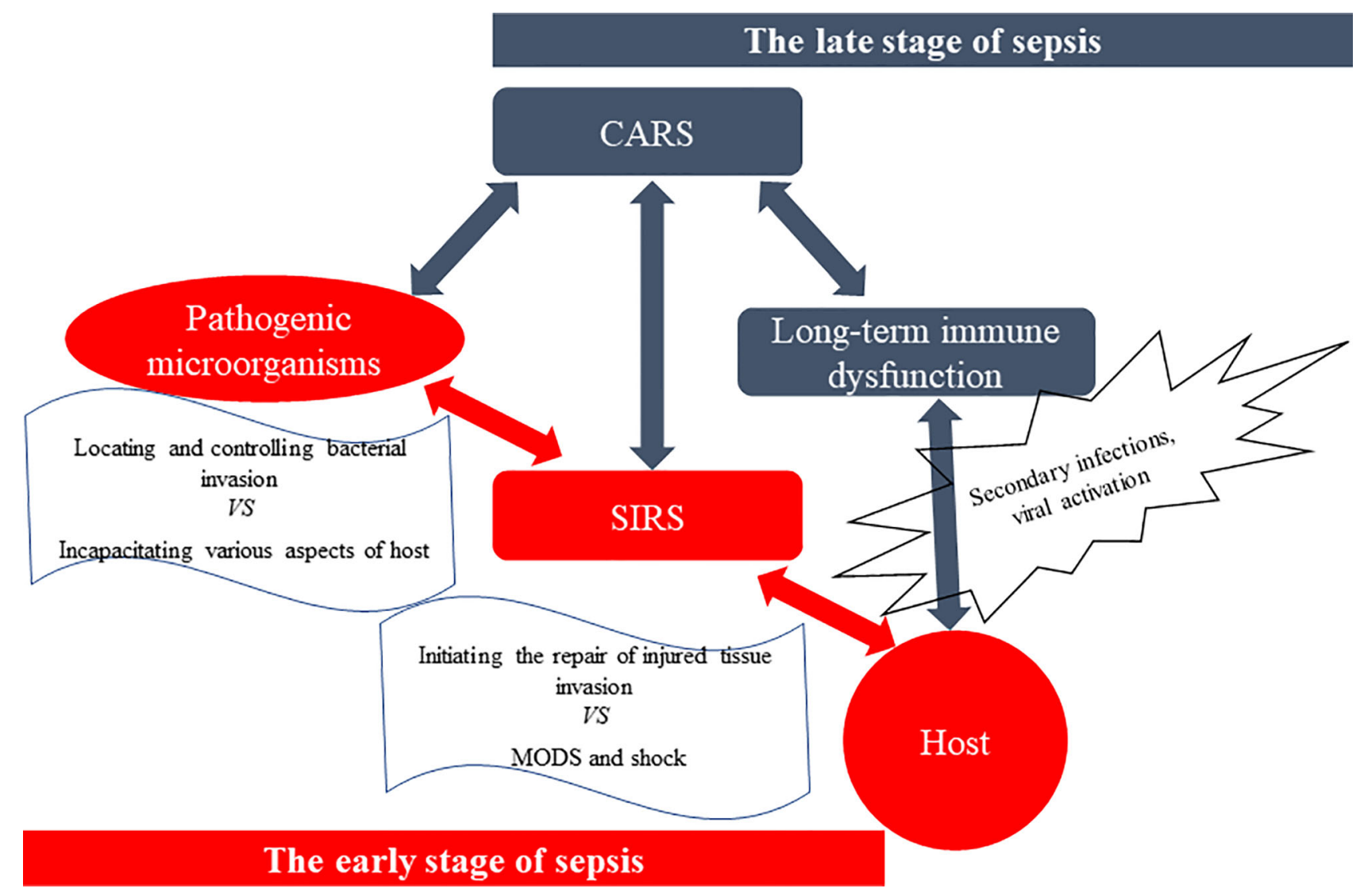

FIGURE 2 | The antagonism between the host and pathogenic microorganisms. The spread of pathogens, especially Gram-negative bacteria, and their products [such as lipopolysaccharide (LPS), etc.] causes systemic inflammatory response syndrome (SIRS), which leads to multiple organ dysfunction syndromes (MODS) and shock, and even death. However, surviving patients suffer from a stage of compensatory anti-inflammatory response syndrome (CARS), especially

immunosuppression, and experience a long-term immune dysfunction called immuno-paralysis. And they are more susceptible to secondary infections, increased viral activation, and reduced 5-year survival rate, compared to those who do not have sepsis.

most patients survive the SIRS-induced "cytokine storm" in the early stage of sepsis and begin the late stage dominated by compensatory anti-inflammatory response syndrome (CARS) (44-46). Compelling experimental and clinical evidence has indicated that SIRS and CARS occur early and simultaneously in sepsis, and immunosuppression may persist for months or even longer from the onset of sepsis (4, 15, 26, 45-51). Importantly, immunosuppression is the cause of such aggravation, which increases the chance of secondary infections and viral activation. This complicates multiple organ dysfunction syndromes (MODS), extends hospital length of stay, and may even leads to death $(15,45,46,49)$.

Approximately $60-70 \%$ of septic deaths occur in the late stage ( $\geq 3$ days) and most deaths were associated with ICU-acquired complications, including nosocomial infections (52). T cell apoptosis and dysfunction contributes to sepsis-induced immunosuppression $(15,26,46,53,54)$. Intervention strategies, such as anti-programmed cell death (PD)-1/PD-L1 $\mathrm{mAb}$, blocking cytotoxic T lymphocyte antigen (CTLA)-4, and blocking 2B4, have improved survival in experimental models of sepsis and recent clinical trials through improved $\mathrm{T}$ cell-induced immunosuppression $(46,55-58)$. The degree of sepsis-induced inflammation, including the level of immunosuppression, is defined by specific host factors (such as age, gender, alcoholism, repeated nosocomial infection, frequency in hospital, chronic comorbidities, immunosuppressant use, malignant tumor, site of infection, splenectomy, trauma, and stress state) (59-66), pathogen status (such as multiple drugresistant organisms, malaria, SARS-CoV-2) $(7,26,67,68)$, and the duration of sepsis $(6,28,35,44,46,61,69,70)$.

\section{TREG HETEROGENEITY IN SEPSIS}

Combined single-cell, TCR, and other analyses of Tregs and conventional CD4+Foxp3- T cells (Tconv) demonstrate that Tregs are highly heterogeneous cells in homeostasis and disease (71-73). Treg cells can be either thymus-derived or peripherally induced by naive CD+ T cells. Phenotypically, Tregs are identified by markers they possess such as the transcriptional regulator Forkhead box (Foxp3). Based on the expression levels of Foxp3, 
Tregs can be either resting Tregs with weak inhibitory potential, activated Tregs with strong inhibitory potential, or cytokine secreting non-suppressive Tregs also called effector Tregs (74). Sepsis influences the heterogeneous characteristics of Tregs from the aspects of percentage $(22,74)$, absolute number $(67,75)$, phenotypes $(15,47,50,58,75-79)$, cytokine and chemokine secretion (80-82), and stability (12, 13, 60) (Tables 1-4). Coordination between the innate and adaptive immune systems plays a crucial role in the host's responses to infection. Even after sepsis recovery, the mechanism and cellular characteristics of the immune system change due to the different characteristics of host immune and pathogen status $(23,59-65,84,105,120,121)$.

Over the past decade, evidence from many compelling experiments and clinical trials indicates that sepsis increases the heterogeneous characteristics of Tregs. They act on both the innate and adaptive immune systems, dampening immune functions, causing immuno-paralysis, and eventually leading to MODS and death in sepsis $(14,18,122-125)$. Intervention strategies (Tables 3 and 4), such as human recombinant cytokines (IL-15 and IL-36) $(59,101)$, blocking phenotypes or chemokines [neuropilin (Nrp)1, CTLA-4, lymphocyte activation gene (LAG)-3, and chemokine (C-X-C motif) ligand (CXCL) 4)] (50, 58, 77, 82), nutrients (glutamine) (107), inhibiting molecules [sema3A, tissuenonspecific alkaline phosphatase (TNAP), Sirtuin1, P2Y12, COX-2, and poly ADP-ribose polymerase (PARP)] (48, 51, 102, 111-113), as well as even clinical therapeutics (high-volume hemofiltration, immunoglobulin, fresh frozen plasma, stem cells, and ulinastatin) $(41,114,115,117,118)$ and traditional Chinese medicine (TCM) (electroacupuncture and tanshinone IIA) $(103,106)$, can increase the chance of survival by inhibiting the heterogeneous characteristics of Treg-induced immunosuppression. Alternatively, other studies have shown improved outcomes in sepsis by increasing the heterogeneous characteristics of Tregs to inhibit sepsis-induced SIRS through intervention strategies such as human recombinant cytokines (IL38 and IL-7) $(96,97)$, blocking phenotypes or cytokines (CD28 and IL-3) (81, 95), nutrients (arginine and fiber cellulose) (108, 109), and others (bilirubin, ITK inhibitor, miR-126, maresin1, excretory-secretory products of Trichinella spiralis adult worms, and adipose-derived mesenchymal stem cell-derived exosomes) $(19,20,70,98,99,116)$, as well as even clinical therapeutics (enteral nutrition and pre-and post-dilution during continuous veno-venous hemofiltration) $(22,42,119)$ and TCM (baicalin, rhubarb, Xuebijing injection, and curcumin) (21, 100, 104, 105). Establishment of sepsis models such as the "memory mouse" (57, 95), "two- or three-hit mouse" (70, 118), and "gene recombination mouse" models $(78,79,94)$ have begun to shed light on additional heterogeneous immune characteristics in sepsis, including the presence of $\mathrm{IL}-10+$ regulatory $\mathrm{B}$ cells (Bregs) and lipopolysaccharide-responsive beige-like anchor protein (LRBA)deficient patients $(97,126,127)$.

\section{TREG CHECKPOINTS IN SEPSIS}

Multiple co-stimulatory molecules (CD28, CD27, OX40, and 41BB) (128-130) and co-inhibitory receptors [B- and T-lymphocyte attenuator (BTLA), T cell immunoglobulin and mucin domaincontaining-3 (TIM-3), CTLA-4, T cell immunoreceptor with immunoglobulin and ITIM domains (TIGIT), LAG-3, PD-1, and Nrp-12] $(15,50,57,77,93,131)$ that transmit various secondary signals play a pivotal role in the heterogeneous characteristics of Tregs and may contribute to Tregs-induced dysfunction of the whole immune system in sepsis, especially imbalanced Tregs/ Tconvs $(15,74-77,83,132,133)$. Although the innate immune system is dominant in the early stage of sepsis, Tregs are thought to be the link between the innate and adaptive immune systems $(37,40)$.

The percentage of Tregs, OX40+ Tregs, and 4-1BB+ Tconvs were higher in the early stage of CAP-associated septic patients. The percentage of CD4+CD27+, CD4+CD28+, and CD4+OX40 + CD27-CD28- T cells were positively correlated with SOFA and predicted 28-day mortality, respectively (40). In addition, these data indicated that imbalanced expression of OX40 and 4-1BB may contribute to evaluate the imbalance of Tregs/Tconvs. The absolute number of CD4+TIM-3+, CD4+PD-1+, and CD4 +CTLA-4+ T cells were positively correlated with the severity of sepsis, especially CD4+PD-1+ T cells, which may be a risk factor for sepsis (93). BTLA is a co-inhibitory receptor that is constitutively expressed on IL-10+Tregs, which can effectively inhibit the function of CD4+ T cells (15). BTLA expression on Tregs remained high in patients with sepsis, compared to healthy controls from day 1 to 7 , especially in non-survivors (75). GPR174, a member of the G-protein-coupled receptor family, plays a negative role in the development and functionality of Tregs which is highly expressed on the surface of Tregs in the early stages of sepsis and closely associated with adverse sepsis outcomes (79). A decrease of Human Leukocyte Antigen-DR (HLA-DR) expression on monocytes has proved to be a reliable indicator of immunosuppression in sepsis $(37,41,60)$. From day 1 to 28 after sepsis diagnosis, both Foxp3 and RORC, the specific transcription factor of Tregs and Th17 cells, respectively, were significantly more highly expressed in survivors than in nonsurvivors. The lack of a linear correlation with HLA-DR may be due to the influence of sample size and other patient-specific factors (60). Thymus Stromal Lymphopoietin (TSLP) has been identified as a crucial inflammatory cytokine in immune homeostasis and promoted Tregs differentiation (134). The percentage of IL-10+ Tregs significantly increased in septic patients with high TSLP levels (80). A comprehensive study on the expression of co-stimulatory molecules and co-inhibitory receptors in different stages of sepsis induced Tregs would contribute to the systematic understanding of Tregs in sepsis and help people identify the most effective immune checkpoints for Tregs.

\section{HOST-DEPENDENT TREG PATTERNS IN SEPSIS}

Compelling experimental and clinical evidence has indicated that sepsis is a multi-dimensional heterogeneous syndrome, which is reflected in the host's variable immune responses $(23,135,136)$. 
TABLE 1 | Observational studies using animal models focused on the characteristics of $T_{\text {regs }}$ in sepsis.

\begin{tabular}{|c|c|c|c|c|c|c|c|}
\hline $\begin{array}{l}\text { Observational } \\
\text { study }\end{array}$ & Species & Model & Observation time & $\begin{array}{l}\text { Specimen } \\
\text { Source }\end{array}$ & $T_{\text {regs }}$ & $\begin{array}{l}\text { Immunological } \\
\text { characteristics }\end{array}$ & Outcome \\
\hline \multirow[t]{2}{*}{ He, et al. (23) } & Mouse & $\begin{array}{l}\text { Recurrent sepsis (Three } \\
\text { LPS stimulations, once } \\
\text { every } 5 \text { ds) }\end{array}$ & $\begin{array}{l}5 \text { ds after the last LPS } \\
\text { injection }\end{array}$ & $\begin{array}{l}\text { Spleens } \\
\text { Lung }\end{array}$ & $\begin{array}{l}\text { Percentage and absolute } \\
\text { number } \uparrow\end{array}$ & $\begin{array}{l}\text { percentage and number of } \\
\text { CD4 } 4^{+} T \text { cells } \downarrow \\
\text { Percentage of } C D 8^{+} T \text { cells } \downarrow \\
\text { CD69 and CD28 of CD4 } \\
\text { cells } \downarrow \\
\text { PD- } 1 \text { and Tim- } 3 \text { of } C D 4^{+} T \\
\text { cells } \uparrow \\
\text { MHC-ll of antigen-presenting } \\
\text { cells } \downarrow\end{array}$ & $\begin{array}{l}\text { Antiviral immune responses (secondary } \\
\text { virus infection) } \downarrow\end{array}$ \\
\hline & & $\begin{array}{l}\text { Acute sepsis (One LPS } \\
\text { stimulations) }\end{array}$ & $\begin{array}{l}12,24 \text {, and } 48 \text { hs after } \\
\text { LPS injection }\end{array}$ & & Percentage $\uparrow$ & $\begin{array}{l}\text { Percentage and number of } \\
\text { total T cells } \downarrow \\
\text { percentage and number of } \\
\text { CD4/8 } 8^{+} T \text { cells } \downarrow \\
\text { CD69 at } 12 \mathrm{hs} \uparrow, 24 \text {, and } 48 \\
\text { hs } \downarrow \\
\text { MHC-ll of antigen-presenting } \\
\text { cells } \uparrow\end{array}$ & $\begin{array}{l}\text { Antiviral immune responses (secondary } \\
\text { virus infection) } \rightarrow\end{array}$ \\
\hline Gaborit, et al. (83) & Mouse & $\begin{array}{l}\text { Pseudomonas aeruginosa } \\
\text { induced "two-hit" model }\end{array}$ & $\begin{array}{l}\text { Day } 3 \text { for T cell } \\
\text { phenotype } \\
\text { Day } 4 \text { for lung injury in } \\
\text { the double-hit model }\end{array}$ & $\begin{array}{l}\text { Spleens } \\
\text { Lung }\end{array}$ & $\begin{array}{l}\text { Activation } \uparrow \\
\text { TNFR2 } 2^{\text {pos }} \text { Tregs } \uparrow \\
\text { Gizmo, Mki67 (Ki67), Irf4, } \\
\text { Prdm1 (Blimp 1) } \\
\text { and Havcr2 (TIM-3) } \uparrow \\
\text { CD62, CD25, CTLA-4 and } \\
\text { IL-10 } \\
\text { percentage } \uparrow\end{array}$ & $\begin{array}{l}\text { Number of splenic } \mathrm{CD} 4^{+} \mathrm{T} \\
\text { cells } \downarrow\end{array}$ & Susceptibility to secondary pneumonia $\uparrow$ \\
\hline Saito, et al. (84) & Mouse & CS-induced model SAE & $\begin{array}{l}24 \mathrm{hs}, 6,810 \text {, and } 30 \\
\text { ds after induced }\end{array}$ & $\begin{array}{l}\text { Brain } \\
\text { Blood } \\
\text { Spleen and other } \\
\text { lymph nodes }\end{array}$ & $\begin{array}{l}\text { Percentage and absolute } \\
\text { number (brain) } \downarrow\end{array}$ & $\begin{array}{l}\text { Microglia, neuroinflammation, } \\
\text { and neutrophil infiltration } \\
\text { (brain) } \uparrow \\
\text { astrocytes (brain) } \downarrow \\
C D 4 / 8^{+} T \text { cell accumulation } \\
\text { (brain) } \uparrow \\
T \text { cell (blood and spleen) } \downarrow\end{array}$ & $\begin{array}{l}\text { The brain-blood barrier was disrupted } \\
\text { (24hs) } \\
\text { Anxiety-like behaviors } \uparrow \\
\text { Marble burying test } \uparrow \\
\text { Open-field test } \downarrow \\
\text { Forced swimming test } \downarrow \\
\text { Depression }\end{array}$ \\
\hline George, et al. (17) & Mouse & $\begin{array}{l}\text { Acute DenV infection and } \\
7 \text { days later followed with } \\
\text { listeria monocytogenes } \\
\text { induced "two-hit" sepsis }\end{array}$ & $\begin{array}{l}3,7,10,15 \text { ds after } \\
\text { induced }\end{array}$ & $\begin{array}{l}\text { Spleen } \\
\text { Blood }\end{array}$ & $\begin{array}{l}\text { Proliferation (number and } \\
\text { percentage) } \\
\text { GITR, CTLA-4, Foxp3, } \\
\text { CD40L, CD44, CD62L, } \\
\text { and CD69 } \\
\text { IL-10, and TGF- } \beta \uparrow\end{array}$ & $\begin{array}{l}\text { CD4/CD8 }{ }^{+} T \text { cell responses } \downarrow \\
\text { IFN- } \gamma \downarrow\end{array}$ & $\begin{array}{l}\text { Susceptibility } \uparrow \\
\text { Attenuates DHF/DSS }\end{array}$ \\
\hline Baek, et al. (85) & Preterm pigs & $\begin{array}{l}\text { LPS stimulated } \\
\text { Staphylococcus } \\
\text { epidermidis challenge }\end{array}$ & $\begin{array}{l}6,12 \text {, and } 24 \mathrm{hs} \text {, day } 5 \text {, } \\
7 \text {, and } 9 \text { after stimulated } \\
\text { or challenged }\end{array}$ & $\begin{array}{l}\text { Cord blood } \\
\text { Blood }\end{array}$ & $\begin{array}{l}\text { Percentage and absolute } \\
\text { number } \uparrow\end{array}$ & $\begin{array}{l}\text { Genes related to both innate } \\
\text { and adaptive immunity } \downarrow \\
\text { Blood neutrophil and platelet } \\
\text { counts } \downarrow \\
\text { Neutrophil phagocytosis } \\
\text { capacity } \downarrow\end{array}$ & $\begin{array}{l}\text { Severe septic responses } \uparrow \\
\text { 9-ds incidence and severity of } \\
\text { spontaneous infections } \uparrow \\
\text { Overall birth weight } \downarrow\end{array}$ \\
\hline Shrestha, et al. (86) & Neonatal mouse & $\begin{array}{l}\text { LPS stimulated once daily } \\
\text { on postnatal days (PNDs) } \\
3-5\end{array}$ & PND7 or PND14 & Lung & $\begin{array}{l}\text { Percentage and absolute } \\
\text { number } \downarrow\end{array}$ & $\begin{array}{l}\text { CCL2, CCL3, CXCL1, IL-1 } \\
\text { and TNF- } \alpha \uparrow \\
I L-10 \uparrow\end{array}$ & $\begin{array}{l}\text { Survival } \downarrow \\
\text { Body weight } \downarrow \\
\text { Alveolar simplification } \uparrow\end{array}$ \\
\hline
\end{tabular}




\begin{tabular}{|c|c|c|c|c|c|c|c|}
\hline $\begin{array}{l}\text { Observational } \\
\text { study }\end{array}$ & Species & Model & Observation time & $\begin{array}{l}\text { Specimen } \\
\text { Source }\end{array}$ & $T_{\text {regs }}$ & $\begin{array}{l}\text { Immunological } \\
\text { characteristics }\end{array}$ & Outcome \\
\hline & & & & & & & $\begin{array}{l}\text { Pulmonary vascular simplification } \uparrow \\
\text { Lung cell proliferation } \downarrow \text {, and apoptosis } \uparrow\end{array}$ \\
\hline \multirow[t]{3}{*}{ Qiu, et al. (79) } & \multirow{3}{*}{$\begin{array}{l}\text { G protein- } \\
\text { coupled receptor } \\
174-\text { KO Mouse }\end{array}$} & \multirow{3}{*}{$\begin{array}{l}\text { LPS stimulated } \\
\text { CLP }\end{array}$} & \multirow{3}{*}{$\begin{array}{l}24 \text { hs after stimulated or } \\
\text { challenged }\end{array}$} & \multirow{3}{*}{$\begin{array}{l}\text { Thymus } \\
\text { Lung }\end{array}$} & \multirow{3}{*}{$\begin{array}{l}\text { Ctla- } 4, \text { Pdcd- } 1 \text {, and IL- } \\
10 \uparrow \\
\text { CTLA-4 and IL-10个 }\end{array}$} & \multirow{3}{*}{$\begin{array}{l}\text { M2 macrophages } \uparrow \\
\text { IL-6 and TNF- } \alpha \downarrow\end{array}$} & 2 and 7 -ds survival $\uparrow$ \\
\hline & & & & & & & Resistant to inflammatory shock $\uparrow$ \\
\hline & & & & & & & Lung injury $\downarrow$ \\
\hline \multirow[t]{3}{*}{ Zhou, et al. (87) } & \multirow[t]{3}{*}{ PTEN $^{M-K}$ Mouse } & \multirow[t]{3}{*}{ LPS-induced ALI } & \multirow[t]{3}{*}{24 hs after induced } & Blood & \multirow{3}{*}{$\begin{array}{l}\text { Percentage and absolute } \\
\text { number } \uparrow \\
\text { Foxp3 and TGF- } \beta \uparrow\end{array}$} & TGF- $\beta \uparrow$ & 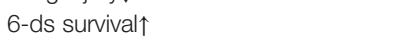 \\
\hline & & & & Lung & & Neutrophil accumulation $\downarrow$ & Lung injury $\downarrow$ \\
\hline & & & & BALF & & $\begin{array}{l}\text { ROR } \gamma t \text {, IL-17A, TNF- } \alpha \text {, and } \\
\text { IL-1 } 1 \beta \downarrow\end{array}$ & Weight $\uparrow$ \\
\hline Andrade, et al. (88) & Mouse & $\begin{array}{l}\text { Received LPS injection } \\
\text { each day for } 5 \text { days, and } \\
\text { followed with CLP }\end{array}$ & 4 hs after CLP & $\begin{array}{l}\text { Spleen } \\
\text { Blood }\end{array}$ & $\begin{array}{l}\text { Absolute number (received } \\
\text { LPS injection) } \uparrow \\
\text { Absolute number (after } \\
\text { CLP) } \downarrow\end{array}$ & 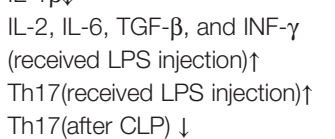 & 72-hs survival $\uparrow$ \\
\hline \multirow[t]{4}{*}{ Cao, et al. (89) } & \multirow[t]{4}{*}{$\mathrm{TLR}^{-/-}$mouse } & \multirow[t]{4}{*}{ CLP } & \multirow[t]{4}{*}{24 hs after CLP } & Lung & \multirow{4}{*}{$\begin{array}{l}\text { Percentage and absolute } \\
\text { number } \downarrow \\
\text { Apoptosis } \downarrow \\
\text { Foxp3 and T/r } 4 \downarrow\end{array}$} & IL-10 and IL-4\ & \multirow{4}{*}{$\begin{array}{l}\text { 72-hs survival } \uparrow \\
\text { Lung, liver injury } \downarrow\end{array}$} \\
\hline & & & & Liver & & IL-2 and TNF- $\alpha \uparrow$ & \\
\hline & & & & Spleen & & & \\
\hline & & & & Blood & & & \\
\hline Fay, et al. (78) & $\mathrm{CD} 43^{-/-}$mouse & CLP & 24 hs after CLP & Spleens & Percentage $\downarrow$ & $\begin{array}{l}\text { Number of CD } 4^{+} T \text { cells } \downarrow \\
\text { Numbers of CD } 4 / 8^{+} \text {central } \\
\text { memory and effector memory } \\
\text { cells } \downarrow \\
\text { Apoptosis of central memory } \\
T \text { cells } \uparrow \\
\text { IL-2-secreting CD4+ T cells } \downarrow \\
\text { IL-4-secreting CD4+ T cells } \uparrow \\
\text { Th17 } \downarrow\end{array}$ & 7-ds survival $\downarrow$ \\
\hline Bomans, et al. (69) & Mouse & CLP & 3 months after CLP & $\begin{array}{l}\text { Spleens } \\
\text { Blood } \\
\text { Bone marrow }\end{array}$ & Percentage (spleens) $\uparrow$ & $\begin{array}{l}\text { Enlarged spleens with higher } \\
\text { weights } \uparrow \\
\mathrm{CD} 11 \mathrm{~b}^{+} \mathrm{F} 4 / 80^{-} \text {splenic } \\
\text { monocytes } \uparrow \\
\text { Ly6C }^{+} \text {inflammatory } \\
\text { monocytes } \uparrow \\
\text { Ly6C } \\
\mathrm{CD}^{-} \text {alternative monocytes } \downarrow \\
\text { macrophages } \uparrow\end{array}$ & $\begin{array}{l}\text { There is no long-term impact of sepsis } \\
\text { on the systemic immune response in } \\
\text { mice } 12 \text { weeks after CLP. }\end{array}$ \\
\hline Ahmadi, et al. (64) & Tumor mouse & $\begin{array}{l}\text { Induction of systemic } \\
\text { candidiasis }\end{array}$ & 8 ds after induction & $\begin{array}{l}\text { Blood } \\
\text { Spleens } \\
\text { Renal } \\
\text { Liver }\end{array}$ & $\begin{array}{l}\text { Percentage (spleens and } \\
\text { tumor) } \uparrow\end{array}$ & $\begin{array}{l}\text { ratio of IFN- } \gamma / \mathrm{LL}-4 \downarrow \\
\mathrm{IL}-10 \uparrow\end{array}$ & Relative tumor volume $\uparrow$ \\
\hline Hu, et al. (90) & Mouse & $\begin{array}{l}\text { Injected with PC61 before } \\
\text { a two-hit model }\end{array}$ & 24 hs two-hit & $\begin{array}{l}\text { Lung } \\
\text { BLFC } \\
\text { Spleens }\end{array}$ & $\begin{array}{l}\text { Percentage and absolute } \\
\text { number } \downarrow\end{array}$ & 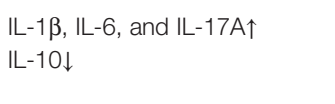 & $\begin{array}{l}3 \text { and } 7 \text {-ds survival } \uparrow \\
\text { Bacterial colonies } \downarrow \\
\text { Lung injury } \downarrow\end{array}$ \\
\hline
\end{tabular}

Compared with the control group, " $\uparrow "$ represents up-regulation, increase or enhancement ; " $\downarrow$ " represents down-regulation, decrease or inhibition, and " $\rightarrow$ " represents no change. 
TABLE 2 | Observational studies using septic patients or combined animal models focused on the characteristics of $T_{\text {regs }}$ in sepsis.

\begin{tabular}{|c|c|c|c|c|c|c|c|}
\hline $\begin{array}{l}\text { Observational } \\
\text { study }\end{array}$ & Species & Model & $\begin{array}{l}\text { Observation } \\
\text { time }\end{array}$ & $\begin{array}{l}\text { Specimen } \\
\text { Source }\end{array}$ & $T_{\text {regs }}$ & Immunological characteristics & Outcome \\
\hline Yin, et al. (74) & Humans & $\begin{array}{l}\text { Severe sepsis/septic } \\
\text { shock patients with } \\
\text { severe neutropenia }\end{array}$ & $\begin{array}{l}\text { Day of PICU } \\
\text { admission }\end{array}$ & Blood & Percentage $\uparrow$ & CRP, PCT, IL-6, IL-10, and IFN- $\gamma \uparrow$ & 28-ds survival $\downarrow$ \\
\hline Jiang, et al. (76) & Humans & Septic patients & $\begin{array}{l}\text { Day of ICU } \\
\text { admission }\end{array}$ & Blood & $\begin{array}{l}\mathrm{PD}-1 \uparrow \uparrow \\
\mathrm{CD} 28, \mathrm{PD}-\mathrm{L} 1 \text {, and } \\
\mathrm{CD} 86 \uparrow\end{array}$ & No data & $\begin{array}{l}\text { SOFA scores } \uparrow \\
28 \text {-ds survival } \downarrow\end{array}$ \\
\hline Youssef, et al. (91) & Neonates & Vitamin D deficiency & After enrolled & Cord blood & Percentage $\downarrow$ & $\begin{array}{l}\text { Total lymphocytes, } \mathrm{CD}^{+} \mathrm{T} \text { lymphocytes, } \\
\mathrm{CD4^{+ }} \text {-helper, CD8 } 8^{+} \mathrm{T} \text {-cytotoxic } \\
\text { lymphocytes, and } \mathrm{CD} 4^{+} \mathrm{CD} 45 \mathrm{RA} A^{+} \text {naïv } \\
\text { T cells } \downarrow\end{array}$ & $\begin{array}{l}16.27 \% \text { of infants with a } 25-\mathrm{OHD} \text { deficiency were } \\
\text { admitted with sepsis } \\
\text { No cases of sepsis in the normal } 25-\mathrm{OHD} \text { group }\end{array}$ \\
\hline Carvelli, et al. (37) & Humans & Septic shock patients & $\begin{array}{l}24 \text { and } 72 \mathrm{hs} \\
\text { after admission }\end{array}$ & Blood & Percentage $\downarrow$ & $\begin{array}{l}\text { Lymphocytes (CD3 } 3^{+} T \text { cells and } \\
\left.\text { CD }^{-}{ }^{-C D 56} 6^{+} \mathrm{NK}\right) \downarrow \\
\text { HLA-DR } \downarrow \\
\text { Innate lymphoid cells } 1 \text { count } \uparrow \\
\text { Innate lymphoid cells } 2 \text { count } \downarrow \\
\text { Innate lymphoid cells } 3 \text { count } \downarrow \\
\text { Innate lymphoid cells } 3 \text { percentage } \uparrow\end{array}$ & secondary infections $\uparrow$ \\
\hline Arens, et al. (92) & Humans & Abdominal sepsis & Over 5 ds & Blood & $\begin{array}{l}\text { No distinguishable } \\
\text { trends in the } \\
\text { percentage }\end{array}$ & $\begin{array}{l}\text { B and NK cell counts } \downarrow \\
\text { IL-8 } \downarrow \\
\text { Th17 cells } \uparrow\end{array}$ & $\begin{array}{l}\text { Day } 21,5 / 26 \text { patients showed no candida colonization } \\
\text { or invasive candidiasis (IC), } 13 / 26 \text { patients colonization } \\
\text { was detected, and } 8 / 26 \text { patients were diagnosed with } \\
\text { IC. }\end{array}$ \\
\hline Xu, et al. (60) & Humans & Septic patients & $\begin{array}{l}\text { Days } 1,3,5,7 \\
10,14,21 \text { and } \\
28 \text { after sepsis }\end{array}$ & Blood & Foxp3 (survivors) $\uparrow$ & $\begin{array}{l}\text { HLA-DRA (survivors) } \uparrow \\
\text { Th1 and Th2 cells(especially non-survivors) } \downarrow \\
\text { Th17 (survivors) } \\
\text { T-bet (Th1) and GATA-3 (Th2) had a linear c } \\
59 \text { survivors, } 19 \text { non-survivors }\end{array}$ & correlation with HLA-DRA \\
\hline Yu, et al. (80) & Humans & Septic patients & After admission & Blood & $\begin{array}{l}\text { The ratio of } \mathrm{LL}-10^{+} \\
\text {Tregs to total } \\
\text { Tregs } \downarrow\end{array}$ & $\begin{array}{l}\text { TSLP } \uparrow \\
\text { Number of Th1 cells } \uparrow \\
\text { IL-1 } \beta, \text { IL-6, IFN- } \gamma \text {, and TNF- } \alpha \uparrow\end{array}$ & $\begin{array}{l}134 \text { patients had hyperleukocytosis and a high } \\
\text { neutrophil ratio } \\
\text { Mortality } \uparrow \\
\text { Stays in the intensive care unit } \uparrow\end{array}$ \\
\hline Liu, et al. (75) & Humans & Septic patients & Ds 1 and 7 & Blood & \multicolumn{2}{|c|}{$\begin{array}{l}\text { Day } 1 \text {, absolute number (non-survivors) } \downarrow \\
\text { Day } 7 \text {, percentage and absolute number(non-survivors) } \uparrow \\
\text { Day } 7 \text {, percentage } \downarrow \downarrow \text { and absolute number(survivors) } \uparrow \uparrow\end{array}$} & $\begin{array}{l}\text { BTLA expression on Tregs (non-survivors) } \uparrow \uparrow \\
\text { Day } 1 \text {, BTLA on } C D 4^{+} T \text { cells was in patients with } \\
\text { severe sepsis } \downarrow \\
\text { day } 7 \text {, BTLA on CD4 } 4^{+} \text {T-cells in both survivors and } \\
\text { non-survivors } \uparrow \\
\text { BTLATregs were positively correlated with SOFA }\end{array}$ \\
\hline $\begin{array}{l}\text { Greenberg, et al. } \\
\text { (93) }\end{array}$ & Humans & Staphylococcus aureus & $\begin{array}{l}\text { After positive S. } \\
\text { aureus blood } \\
\text { culture }\end{array}$ & Blood & $\begin{array}{l}\text { Associated with } \\
\text { immunosuppressive } \\
\text { medications }\end{array}$ & 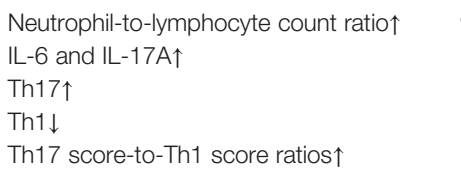 & 90-ds survival $\downarrow$ \\
\hline Lu, et al. (40) & Humans & Septic shock & Within 3 ds & Blood & 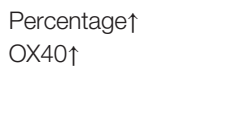 & $\begin{array}{l}\text { CD28, CD27, OX40 on CD4 } 4^{+} T \text { cells } \uparrow \\
\text { OX40 on CD4 } 4^{+} \mathrm{CD} 27^{-} \mathrm{CD} 28^{-} T \text { cells } \uparrow \\
\mathrm{CD} 4^{+} \mathrm{CD} 27^{-} \mathrm{CD} 28^{-} T \text { cells } \downarrow \\
\text { 4-1BB on } \mathrm{CD} 4 / 8^{+} T \text { cells } \downarrow\end{array}$ & $\begin{array}{l}\text { 28-ds survival } \downarrow \\
\text { SOFA } \uparrow\end{array}$ \\
\hline
\end{tabular}




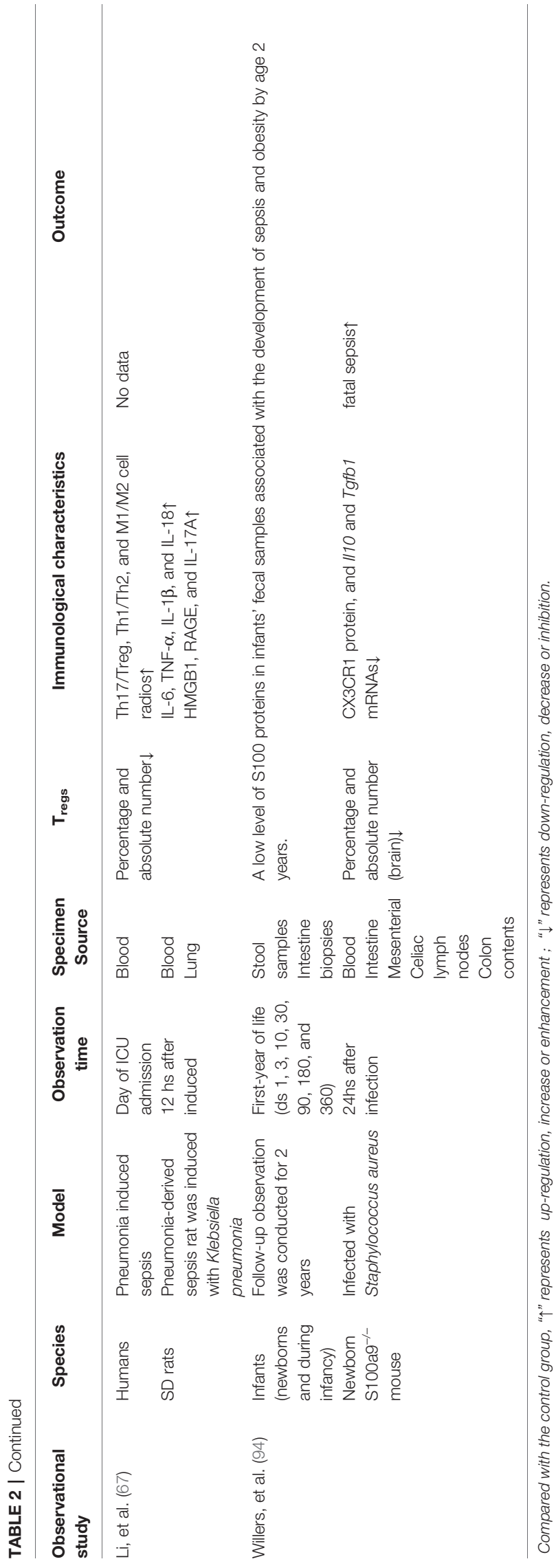

There is significant inter-study heterogeneity among a large number of sepsis-related studies: male sex, increased age, organ dysfunction acquired during ICU stay, recurrent sepsis, and presence of comorbidities are independently associated with increased sepsis-related mortality, especially in ICUs (2, 3, 137). Seymour and colleagues demonstrated that patients with the $\alpha$ phenotype (33\%) have the lowest administration of a vasopressor; Patients with the $\beta$ phenotype (27\%) are the oldest age with the most chronic illness and renal dysfunction; Patients with the $\gamma$ phenotype (27\%) have the most inflammation and pulmonary dysfunction; Patients with the $\delta$ phenotype $(n=2667$; $13 \%)$ have more liver dysfunction and septic shock. Their cumulative 28 -day mortality rates are $5 \%, 24 \%, 13 \%$, and $40 \%$, respectively (135).

Studies of immune responses to sepsis usually exclude patients who have immune disorders or receive immunosuppressive medications $(40,76,80)$; therefore, these studies do not fully reflect the heterogeneous characteristics of sepsis $(91,135)$. An increased Th17/Treg response throughout infection is most strongly associated with increased mortality among patients who are not immunocompromised; a decreased Th1/Treg response is most common among immunocompromised patients. Unexpectedly, patients who have immunocompromising comorbidities or take immunosuppressive medications do not have increased 90-day mortality, contrary to previous studies (138, 139). Immunocompromised patients with malignancies, especially those treated with chemotherapies that have adverse effects on immune function, have broadened the types and risks of drugresistant multi-pathogenic infections (140). For example, systemic infection with Candida albicans (candidiasis) in tumor-bearing mice does not significantly increase the percentage of Tregs compared to the tumor group, but it significantly increases the proportion of Tregs in the spleen of the non-tumor bearing mouse. Surprisingly, systemic infection with C. albicans promotes the rapid growth of tumors, and the percentage of tumor-infiltrated Tregs in the tumor/candidiasis group is significantly higher than these in the tumor only group (64). This demonstrates that candidiasis could promote the growth of tumors by expanding Tregs: tumors and candidiasis promote each other through increased Treg activity. On the other hand, research on common variable immunodeficiency (CVID) and autoimmune diseases, both of which are characterized by loss of Treg function, show that the heterogeneity in sepsis due to host factors has become more prominent $(127,141)$. Autoimmune diseases are associated with a lower risk of 30 -day death (27\% reduction) for sepsis through a mechanism unrelated to the chronic immunomodulation medications (141). LRBA deficiency leads to different types of congenital immune deficiencies, such as CVID, autoimmune lymphoproliferative syndrome (ALPS) with recurrent infections, and even sepsis. Low expression of CTLA-4, Foxp3, and CD25 in LRBA-deficient patients leads to a partial loss of the regulatory effects of Tregs on T/B cell activation and causes an inappropriate increase in T and B cell activation (127).

Some evidence demonstrates that ICU-acquired infections contribute to the overall mortality of septic patients. Patients with septic shock who have secondary infections are at a 5.8 times higher risk of late-stage death than those without because 
TABLE 3 | Intervention studies using animal models focused on the target of $T_{\text {regs }}$ in sepsis.

\begin{tabular}{|c|c|c|c|c|c|c|c|c|c|}
\hline $\begin{array}{l}\text { Intervention } \\
\text { study }\end{array}$ & Species & Model & Intervention & Intervention time & Observation time & $\begin{array}{l}\text { Specimen } \\
\text { Source }\end{array}$ & $T_{\text {regs }}$ & $\begin{array}{l}\text { Immunological } \\
\text { characteristics }\end{array}$ & Outcome \\
\hline Sun, et al. (57) & Mouse & $\begin{array}{l}\text { Memory mouse ( } 56 \mathrm{ds} \\
\text { antigen-experienced) and } \\
\text { CLP }\end{array}$ & TIGIT ( $\alpha$ TIGIT Ab) & 12 and $24 \mathrm{hs}$ after CLP & 48 hs after CLP & $\begin{array}{l}\text { Spleens } \\
\text { Blood }\end{array}$ & 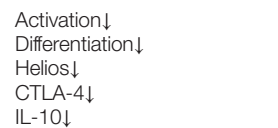 & $\begin{array}{l}\text { Apoptosis of memory T cells } \uparrow \\
\text { T cell function } \downarrow \\
\text { IL-10, LL-6,and MCP-1 } 1 \downarrow\end{array}$ & 7-ds survivalı \\
\hline Sun, et al. (95) & & & $\begin{array}{l}\text { CD28 (agonistic anti- } \\
\text { CD28 Ab) }\end{array}$ & $\begin{array}{l}\text { Immediately after CLP and at ds } 2 \text {, } \\
4 \text {, and } 6 \text { post-CLP }\end{array}$ & $24 \mathrm{hs}$ after CLP & & 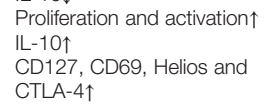 & $\begin{array}{l}\text { Apoptosis of CD } 44^{\text {hi }} \text { memory } \\
\text { CD } 4^{+} T \text { cells } \downarrow \\
\mathrm{IL}-10 \uparrow\end{array}$ & 7 -ds survivalt \\
\hline Tran, et al. (70) & Mouse & $\begin{array}{l}\text { Injected with LPS, and } 24 \\
\text { hs latter CLP induced } \\
\text { "Two-Hit" Model }\end{array}$ & Bilirubin & Immediately after CLP & $24 \mathrm{hs}$ after CLP & $\begin{array}{l}\text { Lung } \\
\text { Blood }\end{array}$ & Percentage $\uparrow$ & $\begin{array}{l}\text { TNF- } \alpha \text {, IL-6, and IFN- } \gamma \downarrow \\
\text { IL-10, and TGF- } \beta \uparrow \\
\text { T cell activation } \downarrow \\
\text { IFN- } \gamma-\text { producing cells } \downarrow\end{array}$ & $\begin{array}{l}\text { 14-ds survival } \\
\text { Lung injury } \downarrow\end{array}$ \\
\hline Ge, et al. (96) & Mouse & CLP & IL-38 (rmlL-38) & $2 \mathrm{hs}$ before or after severe CLP & $48 \mathrm{hs}$ after CLP & Spleens & $\begin{array}{l}\text { Immunosuppressive activity } \uparrow \\
\text { IL-10 and TGF- } \beta 1 \uparrow \\
\text { Foxp3 and CTLA- } 4 \uparrow\end{array}$ & $\begin{array}{l}\text { Th2 response (IL-4) } \uparrow \\
\text { Proliferative ability of } T \text { cells } \downarrow\end{array}$ & 7-ds survival $\uparrow$ \\
\hline Zhao, et al. (81) & Mouse & CLP & IL-3 (siRNA, IL-3 Ab) & 2, 6, and $12 \mathrm{hs}$ after CLP & $48 \mathrm{hs}$ after CLP & $\begin{array}{l}\text { Spleens, lung, } \\
\text { and liver }\end{array}$ & $\begin{array}{l}\text { Foxp3, CTLA-4, IL-10, and } \\
\text { TGF } \beta \uparrow \\
\text { Suppressive activity } \uparrow \\
\text { Percentage } \uparrow\end{array}$ & $\begin{array}{l}\text { Hyper-inflammatory response } \\
\text { (TNF- } \alpha \text { and IFN- } \gamma \downarrow \downarrow \\
\text { Anti-inflammatory response } \\
(\text { IL-10) } \uparrow\end{array}$ & $\begin{array}{l}\text { 5-ds survival } \uparrow \\
\text { Lung and liver injury }\end{array}$ \\
\hline Kulkarni, et al. (97) & Mouse & Stool suspension & $\mathrm{IL}-7$ & Daily from day 5-9 & $\begin{array}{l}3.5 \text { months after } \\
\text { sepsis }\end{array}$ & Spleen & $\begin{array}{l}\text { Percentage and absolute } \\
\text { number (within } 1 \text { week after } \\
\text { sepsis) } \uparrow\end{array}$ & 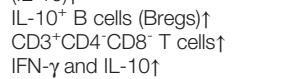 & No data \\
\hline Nadeem, et al. (98) & Mouse & LPS-induced ALI & ITK (inhibitor) & $\begin{array}{l}\text { Once } 30 \text { min before and then } 3 \\
\text { times after LPS administration at } \\
12 \text { hourly intervals }\end{array}$ & $48 \mathrm{hs}$ after LPS & BAL & Percentage $\uparrow$ & $\begin{array}{l}\text { Total leukocytic and } \\
\text { neutrophilic numbers } \downarrow \\
\% \text { IL-17A }{ }^{+} \mathrm{CD} 4^{+} \mathrm{T} \text { cells } \downarrow\end{array}$ & Lung injury $\downarrow$ \\
\hline Zou, et al. (19) & SD rats & CLP & miR-126 (mimic) & Immediately after CLP & $48 \mathrm{hs}$ after CLP & Blood & $\begin{array}{l}\text { Percentage and absolute } \\
\text { number } \uparrow\end{array}$ & 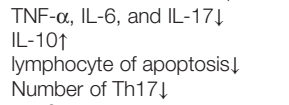 & No data \\
\hline Xia, et al. (20) & Mouse & CLP & Maresin1 & $1 \mathrm{~h}$ after CLP & $24 \mathrm{hs}$ after CLP & $\begin{array}{l}\text { Lung } \\
\text { BALF }\end{array}$ & $\begin{array}{l}\text { Percentage and absolute } \\
\text { number } \uparrow\end{array}$ & $\begin{array}{l}\text { IL- }-1 \beta \text {, TNF- } \alpha, \text { IL- } 6 \text {, and IL- } 17 \downarrow \\
\text { IL-10 and TGF- } \beta \uparrow \\
\text { Th17/Tregs } \downarrow\end{array}$ & $\begin{array}{l}\text { 7-ds survival } \\
\text { Lung injury } \downarrow\end{array}$ \\
\hline Li, et al. (99) & Mouse & CLP-induced ALI & $\begin{array}{l}\text { Excretory secretory } \\
\text { products of Trichinella } \\
\text { spiralis adult worms }\end{array}$ & Immediately after CLP & $12 \mathrm{hs}$ after CLP & $\begin{array}{l}\text { Lung } \\
\text { Blood }\end{array}$ & Percentage $\uparrow$ & 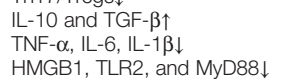 & $\begin{array}{l}\text { 3-ds survival } \\
\text { Lung injury } \downarrow\end{array}$ \\
\hline Liu, et al. (21) & Mouse & $\begin{array}{l}\text { CLP-induced pancreatic } \\
\text { injury }\end{array}$ & Baicalin & Immediately after CLP & 72 hs after CLP & $\begin{array}{l}\text { Blood } \\
\text { Spleen } \\
\text { Pancreatic } \\
\text { tissue }\end{array}$ & 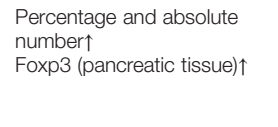 & 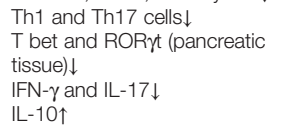 & Pancreatic injury $\downarrow$ \\
\hline Liu, et al. (100) & Rats & Burning model & Rhubarb & Immediately after model & $\begin{array}{l}\text { 12, } 24 \text {, and } 72 \mathrm{hs} \\
\text { after CLP }\end{array}$ & $\begin{array}{l}\text { Liver } \\
\text { Blood }\end{array}$ & $\begin{array}{l}\text { Percentage and absolute } \\
\text { number } \uparrow\end{array}$ & $\begin{array}{l}\text { CD4 } 4^{+} \text {T cell percentage } \downarrow \\
\text { CD8 } \\
\text { CD19 cell percentage } \uparrow \\
\text { NK cell percentage percentage } \downarrow \\
\text { NK } \downarrow\end{array}$ & No data \\
\hline \multirow[t]{2}{*}{ Saito, et al. (59) } & $\begin{array}{l}\text { Young } \\
\text { mouse }\end{array}$ & $\begin{array}{l}\text { day } 0,4,7 \text {, and } 10 \text { to inject } \\
\text { CS }\end{array}$ & $\mathrm{IL}-15$ & Day 3, 7 and 10 & Within 50 days & $\begin{array}{l}\text { Blood } \\
\text { Spleens } \\
\text { Peritoneal } \\
\text { lavage fluids }\end{array}$ & $\begin{array}{l}\text { Percentage and absolute } \\
\text { number } \downarrow\end{array}$ & $\begin{array}{l}\text { Naive CD } 4^{+} T \text { cell } \uparrow \\
\text { PD }-1^{+} \mathrm{CD} 4^{+} T \text { cells } \downarrow \\
\mathrm{CD} 8^{+} T \text { cell } \uparrow\end{array}$ & \multirow{2}{*}{$\begin{array}{l}\text { Prevent the initial } \\
\text { reduction of body } \\
\text { weight (Day 3) } \uparrow \\
\text { Survival } \uparrow \\
\text { Survival } \uparrow\end{array}$} \\
\hline & $\begin{array}{l}\text { Aged } \\
\text { mouse }\end{array}$ & & & & & & $\begin{array}{l}\text { Percentage and absolute } \\
\text { number } \downarrow\end{array}$ & $\begin{array}{l}\mathrm{CD} 4^{+} \mathrm{T} \text { cells } \uparrow \\
\text { Naive } \mathrm{CD} 4^{+} T \text { cell } \uparrow \\
\mathrm{PD}-1^{+} \mathrm{CD} 4^{+} T \text { cells } \downarrow \\
\text { Naiive } \mathrm{CD} 8^{+} \mathrm{T} \text { cells } \uparrow \\
\mathrm{PD}-1^{+} \mathrm{CD} 8^{+} T \text { cells } \downarrow\end{array}$ & \\
\hline Ge, et al. (101) & Mouse & CLP & IL-36 (IL-36ß) & 2 hs before or after CLP & 48 hs after CLP & Spleens & $\begin{array}{l}\text { Tregs were required } \\
\text { IL-10 and TGF- } \beta 1 \downarrow \\
\text { Foxp3 and CTLA- } 4 \downarrow\end{array}$ & $\begin{array}{l}\mathrm{CD} 4^{+} \mathrm{CD} 25^{-} \mathrm{T} \text { cell } \\
\text { proliferation } \uparrow \\
\text { The ratio of IL-4 to IFN- } \gamma \downarrow\end{array}$ & $\begin{array}{l}\text { 7-ds survival ( } 2 \mathrm{hs} \\
\text { before } \mathrm{CLP}) \uparrow\end{array}$ \\
\hline Gao, et al. (50) & Mouse & CLP & Nrp-1 (siRNA, Nrp-1 Ab) & Immediately after CLP & $24 \mathrm{hs}$ after CLP & $\begin{array}{l}\text { Spleens and } \\
\text { renal }\end{array}$ & $\begin{array}{l}\text { Stability and activity (Foxp3, } \\
\text { CTLA-4, TGF- } \beta 1^{m+}, \mathrm{IL}-10 \text {, } \\
\text { and TGF- } \beta 1) \downarrow\end{array}$ & 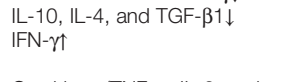 & Renal injury $\downarrow$ \\
\hline Lou, et al. (77) & Mouse & CLP & LAG-3 (KO, LAG-3 Ab) & Immediately after CLP & 24 hs after CLP & $\begin{array}{l}\text { Blood } \\
\text { Spleens }\end{array}$ & $\begin{array}{l}\text { Percentage and absolute } \\
\text { number } \downarrow\end{array}$ & $\begin{array}{l}\text { Cytokines (TNF- } \alpha, \text { IL-6, and } \\
\text { IL-10) and T cells apoptosis } \downarrow \\
\text { IFN- } \gamma \text {, the absolute number } \\
\text { and proliferative ability of CD4/ } \\
8^{+} T \text { cells } \uparrow\end{array}$ & $\begin{array}{l}\text { 7-ds survival } \uparrow \\
\text { Bacterial clearance } \uparrow\end{array}$ \\
\hline
\end{tabular}


TABLE 3 | Continued

\begin{tabular}{|c|c|c|c|c|c|c|c|c|c|}
\hline $\begin{array}{l}\text { Intervention } \\
\text { study }\end{array}$ & Species & Model & Intervention & Intervention time & Observation time & $\begin{array}{l}\text { Specimen } \\
\text { Source }\end{array}$ & $T_{\text {regs }}$ & $\begin{array}{l}\text { Immunological } \\
\text { characteristics }\end{array}$ & Outcome \\
\hline Xu, et al. (82) & Mouse & CLP & CXCL4 (CXCL4 Ab) & Immediately after CLP & 72 hs after CLP & $\begin{array}{l}\text { Urine } \\
\text { Blood } \\
\text { Sploeng }\end{array}$ & $\begin{array}{l}\text { Percentage and absolute } \\
\text { number } \downarrow\end{array}$ & IL-6, LL-10and TNF- $\alpha \downarrow$ & $\begin{array}{l}\text { Urine creatinine and } \\
\text { urea nitrogen } \downarrow\end{array}$ \\
\hline Gao, et al. (48) & Mouse & CLP & $\begin{array}{l}\text { Sema3A (EGCG, a } \\
\text { strong inhibitor of } \\
\text { Sema3A) }\end{array}$ & Immediately after CLP & 24 hs after CLP & $\begin{array}{l}\text { Spleens } \\
\text { Blood }\end{array}$ & Foxp3\ $\downarrow$ & $\begin{array}{l}\text { IL- } 4 \downarrow \\
\text { IFN- } \gamma \uparrow \\
\text { Apoptosis of } C D 4^{+} T \text { cells } \downarrow \\
\text { Proliferative ability of } C D 4^{+} T \\
\text { cells } \uparrow\end{array}$ & $\begin{array}{l}\text { liver, lung, and renal } \\
\text { injury } \downarrow\end{array}$ \\
\hline $\begin{array}{l}\text { Brichacek, et al. } \\
(102)\end{array}$ & Mouse & CLP & $\begin{array}{l}\text { Inhibitor of TNAP (SBI- } \\
\text { 425) }\end{array}$ & Daily for 7 days after CLP & $\begin{array}{l}24 \mathrm{hs} \text { after the final } \\
\text { injection }\end{array}$ & $\begin{array}{l}\text { Plasma } \\
\text { Brain } \\
\text { Bone } \\
\text { Spleens }\end{array}$ & $\begin{array}{l}\text { CD } 4 / 8^{+} \text {Foxp3 } 3^{+} \text {splenocyte T- } \\
\text { cell populations } \downarrow\end{array}$ & \multicolumn{2}{|c|}{$\begin{array}{l}\text { Did not affect 7-ds clinical severity outcomes } \\
\text { Loss of barrier function in BBB endothelial cells } \uparrow \\
48 \text {-hs Survivall } \\
\text { Severity scores } \uparrow\end{array}$} \\
\hline Martin et al. (51) & Mouse & CLP & $\begin{array}{l}\text { Sirtuin1 (EX-527-an } \\
\text { inhibitor) }\end{array}$ & 24 hs after CLP & 30 hs after CLP & Spleen & $\begin{array}{l}\text { Percentage } \downarrow \\
\text { CTLA- } 4 \downarrow\end{array}$ & 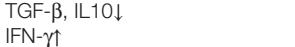 & 7-ds survival^ \\
\hline Gao, et al. (103) & Mouse & CLP & Tanshinone IIA & & $24 \mathrm{hs}$ after CLP & $\begin{array}{l}\text { Blood } \\
\text { Lung } \\
\text { Liver } \\
\text { Renal } \\
\text { Spleens }\end{array}$ & Percentage $\downarrow$ & 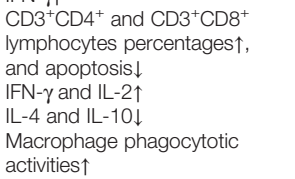 & $\begin{array}{l}7 \text {-ds survival } \uparrow \\
\text { Lung, liver, and renal } \\
\text { injury } \downarrow \\
\text { Intraperitoneal } \\
\text { bacterial counts } \downarrow\end{array}$ \\
\hline Chen, et al. (104) & Mouse & CLP & Xuebijing injection & Immediately after CLP & $\begin{array}{l}36 \text { hs after the } \\
\text { CLP }\end{array}$ & $\begin{array}{l}\text { Spleens } \\
\text { Lung } \\
\text { Renal }\end{array}$ & 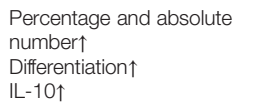 & $\begin{array}{l}\text { Th17」 } \\
\text { |L-17, IL-6, and TNF- } \alpha \downarrow\end{array}$ & $\begin{array}{l}\text { 5-ds survival } \uparrow \\
\text { Renal and lung injury }\end{array}$ \\
\hline Chen, et al. (105) & Mouse & CLP & Curcumin & 12 hs after CLP & $\begin{array}{l}\text { Day } 1,3,5 \text {, and } 7 \\
\text { after CLP }\end{array}$ & $\begin{array}{l}\text { Spleen } \\
\text { Blood } \\
\text { Renal } \\
\text { Lung }\end{array}$ & $\begin{array}{l}\text { Percentage and absolute } \\
\text { number } \uparrow\end{array}$ & $\begin{array}{l}\text { TNF- } \alpha \text { and IL- } 6 \downarrow \\
\text { The proliferation of CD4 } \\
\text { +CD25- T cells } \downarrow \\
\text { IL- } 10 \uparrow\end{array}$ & $\begin{array}{l}\text { Renal and lung injury } \\
\text { 7-ds survival } \uparrow\end{array}$ \\
\hline Xie, et al. (106) & Rats & CLP & Electroacupuncture & Immediately after CLP & 48 hs after CLP & $\begin{array}{l}\text { Spleens } \\
\text { Intestinal } \\
\text { lymph nodes }\end{array}$ & Percentage $\downarrow$ & $\begin{array}{l}\text { TNF- } \alpha \text { and IL- } 10 \downarrow \\
\mathrm{CD}^{+} \mathrm{CD}^{+} \text {cell } \uparrow\end{array}$ & D-LA and DAO $\downarrow$ \\
\hline Hou, et al. (107) & Mouse & CLP & Glutamine & 2 weeks before CLP & $72 \mathrm{~h}$ after CLP & $\begin{array}{l}\text { Blood } \\
\text { Spleens } \\
\text { Renal }\end{array}$ & Percentage $\downarrow$ & $\begin{array}{l}\text { Percentages of } \mathrm{T} \text { and } \mathrm{CD} 4^{+} \mathrm{T} \\
\text { cells } \uparrow \\
\mathrm{IL}-6 \text { and IL- } 4 \downarrow \\
\mathrm{Bcl}-2 \uparrow\end{array}$ & Renal injury $\downarrow$ \\
\hline Yeh, et al. (108) & Mouse & CLP & Arginine & $1 \mathrm{~h}$ after CLP & $\begin{array}{l}12 \text { and } 24 \text { hs after } \\
\text { CLP }\end{array}$ & $\begin{array}{l}\text { Blood } \\
\text { Para-aortic } \\
\text { lymph nodes } \\
\text { Liver }\end{array}$ & Percentage $\uparrow$ & $\begin{array}{l}\text { Percentages of CD4 } 4^{+} T \text { cells } \uparrow \\
\text { Th1/Th2 ratio } \uparrow \\
\text { Th17/Tregs ratio } \downarrow \\
\text { IL-1 } 1 \beta, \text { IL-6, and TNF- } \alpha \text { (liver) } \downarrow\end{array}$ & Liver injury $\downarrow$ \\
\hline $\begin{array}{l}\text { Di Caro, et al. } \\
\text { (109) }\end{array}$ & Mouse & Injected with LPS & $\begin{array}{l}\text { Dietary fiber (fiber } \\
\text { cellulose) }\end{array}$ & 2 weeks before injected with LPS & $\begin{array}{l}24 \text { and } 72 \text { hs post } \\
\text { LPS injection }\end{array}$ & $\begin{array}{l}\text { Blood } \\
\text { Liver } \\
\text { Spleens }\end{array}$ & $\begin{array}{l}\text { Suppressive function } \uparrow \\
\text { Percentage }(72 \mathrm{hs}) \uparrow\end{array}$ & $\begin{array}{l}\text { Number and activation of } \\
\text { splenic macrophages and } \\
\text { DCs } \downarrow \\
\text { Pro-inflammatory cytokines } \downarrow \\
\text { Chemokines } \downarrow \\
\text { Anergy in T cells } \uparrow \\
\text { Hepatic DNA binding activity } \\
\text { of NF-kB } \downarrow\end{array}$ & 4-ds survival؟ (110) \\
\hline $\begin{array}{l}\text { Albayati, et al. } \\
\text { (111) }\end{array}$ & Mouse & CLP & $\begin{array}{l}\text { P2Y12 antagonism } \\
\text { (clopidogre) }\end{array}$ & 2 hs before CLP & 24 hs after CLP & $\begin{array}{l}\text { Blood } \\
\text { Spleens } \\
\text { Hearts } \\
\text { Renal }\end{array}$ & $\begin{array}{l}\text { Percentage and absolute } \\
\text { number (spleens) } \downarrow\end{array}$ & $\begin{array}{l}\text { Platelets and } \mathrm{CD} 4^{+} \mathrm{T} \text { cells } \\
\text { interactions } \downarrow\end{array}$ & $\begin{array}{l}7 \text {-ds survival } \uparrow \\
\text { Splenomegaly and } \\
\text { spleen damage } \downarrow \\
\text { Renal and cardiac } \\
\text { injury } \downarrow\end{array}$ \\
\hline Sun, et al. (112) & Mouse & CLP & $\begin{array}{l}\text { COX-2-specific inhibitor } \\
\text { (parecoxib) }\end{array}$ & 20 min after CLP & 24 hs after CLP & $\begin{array}{l}\text { Blood } \\
\text { Spleens }\end{array}$ & Percentage $\downarrow$ & $\begin{array}{l}\operatorname{IgM} \text { and } \operatorname{IgG} \uparrow \\
\operatorname{IL}-1 \beta, \mathrm{LL}-10 \text {, and TNF- } \alpha \downarrow\end{array}$ & $\begin{array}{l}\text { 7-ds survival } \uparrow \\
\text { Spleen injury } \downarrow\end{array}$ \\
\hline Ahmad, et al. (113) & Mouse & CLP & $\begin{array}{l}\text { Poly (ADP-ribose) } \\
\text { polymerase inhibitor } \\
\text { (Olaparib) }\end{array}$ & $30 \mathrm{~min}$ and $8 \mathrm{hs}$ after CLP & 24 hs after CLP & $\begin{array}{l}\text { Spleens } \\
\text { Blood }\end{array}$ & $\begin{array}{l}\text { Percentage and absolute } \\
\text { number } \downarrow\end{array}$ & 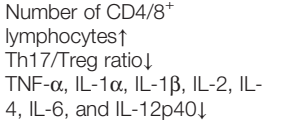 & $\begin{array}{l}\text { 48-hs survival (young, } \\
\text { males) } \uparrow \\
\text { Multiorgan } \\
\text { dysfunction } \downarrow \\
\text { Bacterial CFUs } \downarrow\end{array}$ \\
\hline Cao, et al. (114) & Mouse & CLP & Ulinastatin & $1 \mathrm{~h}$ before and $6 \mathrm{hs}$ after CLP & 24 hs after CLP & $\begin{array}{l}\text { Spleens } \\
\text { Blood } \\
\text { Lung } \\
\text { Liver } \\
\text { Renal }\end{array}$ & Foxp3 and CTLA- $4 \downarrow$ & 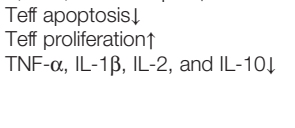 & $\begin{array}{l}\text { 72-hs survival } \uparrow \\
\text { Lung, liver, and renal } \\
\text { injury } \downarrow\end{array}$ \\
\hline
\end{tabular}


TABLE 3 | Continued

\begin{tabular}{|c|c|c|c|c|c|c|c|c|c|}
\hline $\begin{array}{l}\text { Intervention } \\
\text { study }\end{array}$ & Species & Model & Intervention & Intervention time & Observation time & $\begin{array}{l}\text { Specimen } \\
\text { Source }\end{array}$ & $T_{\text {regs }}$ & $\begin{array}{l}\text { Immunological } \\
\text { characteristics }\end{array}$ & Outcome \\
\hline Topcu, et al. (115) & SD rats & CLP & $\begin{array}{l}\text { Human dental follicle } \\
\text { stem cells }\end{array}$ & Immediately or $4 \mathrm{hs}$ after CLP & $24 \mathrm{hs}$ after CLP & $\begin{array}{l}\text { lleal tissue } \\
\text { Spleens }\end{array}$ & Percentage $\downarrow$ & TNF- $\alpha \downarrow$ & \|leal tissue injury $\downarrow$ \\
\hline Chang, et al. (116) & SD rats & Jnfonted ath 5 ogl:01t & $\begin{array}{l}\text { Adipose-derived } \\
\text { mesenchymal stem cell- } \\
\text { derived exosomes }\end{array}$ & $3 \mathrm{hs}$ after CLP & $\begin{array}{l}6,16,24,48, \text { and } \\
72 \text { hs after CLP }\end{array}$ & $\begin{array}{l}\text { Blood } \\
\text { Brain } \\
\text { Cerebrospinal } \\
\text { fluid }\end{array}$ & Percentage $\uparrow$ & 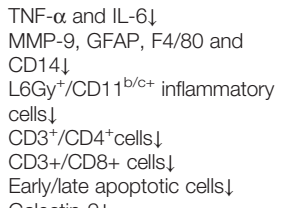 & Brain injury $\downarrow$ \\
\hline Zhang, et al. (117) & Mouse & $\begin{array}{l}\text { Infected with E. coli 0111: } \\
\text { B4 }\end{array}$ & Fresh frozen plasma & $\begin{array}{l}\text { After severe sepsis (trembles, high } \\
\text { fever, and difficulty breathing) }\end{array}$ & $\begin{array}{l}\text { Recovered from } \\
\text { endotoxemia }\end{array}$ & Blood & $\begin{array}{l}\text { Differentiation and } \\
\text { expansion } \downarrow\end{array}$ & 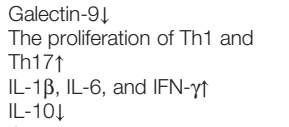 & $\begin{array}{l}\text { Recovered from } \\
\text { endotoxemia } \uparrow\end{array}$ \\
\hline $\begin{array}{l}\text { Kyvelidou, et al. } \\
\text { (118) }\end{array}$ & Mouse & 5 ds injection of LPS & $\lg G$ and $\lg M$ & Day 1 of LPS injection & Day 6 after LPS & $\begin{array}{l}\text { Blood } \\
\text { Spleens }\end{array}$ & CD25 and Foxp3» & $\begin{array}{l}\text { CRP } \downarrow \\
\text { IL- } 6 \text { and TNF- } \alpha \downarrow \\
\text { IL- } 18 \uparrow\end{array}$ & $\begin{array}{l}\text { 7-ds survival } \uparrow \\
\text { MSS scoring } \downarrow\end{array}$ \\
\hline
\end{tabular}

Compared with the control group, "१" represents up-regulation, increase or enhancement ; "l" represents down-regulation, decrease or inhibition.

TABLE 4 | Intervention studies using septic patients focused on the target of $T_{\text {regs }}$ in sepsis.

\begin{tabular}{|c|c|c|c|c|c|c|c|c|c|}
\hline Intervention study & Species & Model & Intervention & Intervention time & Observation time & $\begin{array}{l}\text { Specimen } \\
\text { Source }\end{array}$ & $T_{\text {regs }}$ & $\begin{array}{l}\text { Immunological } \\
\text { characteristics }\end{array}$ & Outcome \\
\hline Liu, et al. (42) & Humans & $\begin{array}{l}\text { Septic Patients } \\
\text { with mechanical } \\
\text { ventilation }\end{array}$ & Enteral nutrition & $\begin{array}{l}\text { Treated within } 48 \\
\text { hs after } \\
\text { admission }\end{array}$ & $\begin{array}{l}\text { D } 1 \text { and } 7 \text { after } \\
\text { admission to the ICU }\end{array}$ & Blood & Percentage $\uparrow$ & Th17 cells and endotoxin $\downarrow$ & $\begin{array}{l}\text { Duration of mechanical } \\
\text { ventilation, lengths of ICU } \\
\text { stay, hospital stay, } \\
\text { And the incidence of ICU- } \\
\text { AW } \downarrow\end{array}$ \\
\hline Sun, et al. (22) & Humans & Septic Patients & Enteral nutrition & $\begin{array}{l}\text { Treated within } 48 \\
\text { hs after admission }\end{array}$ & $7 \mathrm{ds}$ after admission & Blood & Percentage $\uparrow$ & $\begin{array}{l}\text { Th17 percentages } \downarrow \\
\text { Th17/Tregs ratios } \downarrow \\
\text { IL-17, IL-23, and IL-6 } 6\end{array}$ & $\begin{array}{l}\text { Duration of mechanical } \\
\text { ventilation } \downarrow \\
\text { ICU stay } \downarrow\end{array}$ \\
\hline Chihara, et al. (119) & Humans & $\begin{array}{l}\text { Septic shock } \\
\text { patients with acute } \\
\text { kidney injury }\end{array}$ & $\begin{array}{l}\text { Pre-and post-dilution } \\
\text { during continuous } \\
\text { venovenous hemofiltration }\end{array}$ & $\begin{array}{l}24 \text { hs within } \\
\text { obtaining informed } \\
\text { consent }\end{array}$ & $\begin{array}{l}6 \text { and } 24 \text { hs after } \\
\text { continuous } \\
\text { venovenous } \\
\text { hemofiltration }\end{array}$ & Blood & $\begin{array}{l}\text { Induction } \\
\text { rate } \uparrow\end{array}$ & $\begin{array}{l}\text { IL-6 and IL-10 } \downarrow \\
\text { Neutrophil phagocytic } \\
\text { activity } \downarrow\end{array}$ & No data \\
\hline You, et al. (41) & Humans & Severe burn & High-volume hemofiltration & $\begin{array}{l}\text { Within } 3 \text { days after } \\
\text { burn }\end{array}$ & $\begin{array}{l}\text { Days } 1,3,5,7,14,21 \\
\text { and } 28 \text { post-burn }\end{array}$ & Blood & Percentage $\downarrow$ & 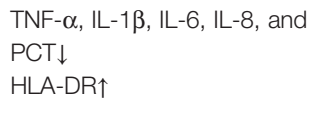 & $\begin{array}{l}\text { Incidence of sepsis, septic } \\
\text { shock } \downarrow \\
\text { Vasopressor } \downarrow \\
\text { 90-ds survival } \uparrow\end{array}$ \\
\hline
\end{tabular}

Compared with the control group, " $\uparrow$ " represents up-regulation, increase or enhancement ; " $\downarrow$ " represents down-regulation. 
of their unique immunosuppressive status, especially $\mathrm{T}$ cell exhaustion caused by aging and recurrent sepsis (2, 23, 52, 59, 142). In a clinically relevant cecal slurry (CS) induced model of recurrent sepsis, increased $\mathrm{T}$ cell exhaustion and poor prognosis (including reduced survival rate and body weight) was observed in aged (18-24 months old) compared with young (5 week old) female or male C57BL6/J mice. Their symptoms persisted for over 50 days and were associated with increased PD-1 expression on Tregs (59). Olaparib, a competitive PARP inhibitor used in the field of oncology that inhibits the binding of NAD+ to the catalytic sites of PARP, showed significant protective effects on cecal ligation perforation (CLP)-induced sepsis in young (8 weeks old) male adult mice compared with aged (72 week old) female mice (143). These age-and sex-selective protective models were associated with olaparib reducing the Treg and Th17 populations, and the Th17/Tregs ratio, by regulating intracellular miRNA levels (113).

In infants, especially preterm infants, early-onset sepsis (EOS) increases the risk of death or neurodevelopmental disorders (144). In a multi-centric clinical study of 326 neonatal intensive care units, $0.8 \%$ of infants suffered from EOS, where many factors reduced lymphocyte activation and the percentage of Tregs, including low Apgar score, caesarean delivery, small gestational age, prenatal antibiotic exposure, vitamin D deficiency, and positive maternal group B streptococcus screening results (145, 146). Intraperitoneal injection of Escherichia coli O55: B5 LPS in neonatal mice reduced survival and growth rates, including lung development, in a dose-dependent manner. These effects were associated with decreases in the percentage of anti-inflammatory CD4+TCR $\beta+$ Foxp3+ Tregs (86).

In addition, multiple clinical studies show that amplification of CD4+CD25+ Tregs and increased Foxp3 levels may increase risks of nosocomial infections or secondary infections in sepsis (61, 68, 147). Using a "two-hit" CLP model with intratracheal injection of Pseudomonas aeruginosa, which mimics clinical conditions of secondary infection, $\mathrm{Hu}$ et al. demonstrated that the absolute number of Foxp3+ Tregs in both spleen and lungs increased 24 hours after secondary $P$. aeruginosa infection. After injection of PC61 (depletion of Tregs via CD25), the absolute numbers of Tregs in the spleens and lungs of septic mice were reduced by $50 \%$ and $60 \%$, respectively. Partial Treg depletion increased IL-17A, IL-1 $\beta$, and IL- 6 secretion, and decreased IL-10 secretion, in septic mice infected with $P$. aeruginosa, thereby reducing the bacterial load and lung injury, and improving 7-day survival (90). On the other hand, 8-week-old male C57 mice with simulated repeat infection by repeated subcutaneous injection of LPS were able to resist CLP-induced sepsis and hyper inflammatory response. These mice had an increased absolute number of Tregs and Th17 and decreased ratio of Th17/Tregs (88). However, ICU studies with critically ill lymphocytopenia patients suggested that the first three days of septic shock may be characterized by a skewed distribution of circulating innate lymphoid cells (ILC), with an excess of ILC1 and a lack of ILC3. At the same time, there was a significant decrease in the absolute number of circulating Tregs (37). These conflicting studies in both mice and humans highlight the heterogeneous nature of Tregs in sepsis that vary upon host conditions.

\section{TISSUE-SPECIFIC TREG PATTERNS IN SEPSIS}

In addition to the role Tregs play in maintaining immune homeostasis in dedicated lymphoid tissues, these cells exist in other tissues such as the lung, liver, renal, muscle, brain and myocardium $(73,87,98,99,102,148)$. Many tissue-specific Treg functions go beyond our initial understanding of Tregs as immune inflammation-specific inhibitors (70, 99, 133). However, most previous interventional and observational studies on sepsis have focused on the functions and characteristics of Tregs in the peripheral circulation and spleen $(41,48,76,96,101)$. Splenectomy improved 28 - day survival in a secondary sepsis CLP mouse model from $62 \%$ to $92 \%$, which was concurrent with the lower release of inflammatory cytokines (IL6, CXCL-1, and MCP-1) and a $41 \%$ increase in Tregs within 48 hours (65). This indicates that induced circulating Tregs (iTregs), rather than natural Tregs (nTregs) originating in the spleen, may play a role in improving sepsis survival. Sepsis has tissue-specific pathophysiological characteristics due to anatomical and histological constraints: the structure, morphology, and composition of the vasculature system vary across different organs (149-151). In mice infected with Pseudomonas aeruginosa, the absolute number of Foxp3+ Tregs in lung tissue increased nearly 2 -fold on the third day, then gradually decreased and returned to normal on the seventh day. However, the absolute number of Foxp3+ Tregs in the spleen increased 1.6fold on the third day and continued to increase (90).

Acute lung injury (ALI) or acute respiratory distress syndrome (ARDS) is a type of respiratory failure caused by trauma, infection (sepsis), or intoxication (152, 153). The pathophysiological mechanism of ALI/ARDS is characterized by rapid onset of widespread lung inflammation $(87,135,154)$. A growing body of evidence shows that CD4+CD25+Foxp3+Tregs play a positive role in alleviating sepsis-induced rapid onset inflammation and improving the outcome of ALI/ARDS through both TGF- $\beta$-dependent and independent pathways $(20,22,42$, $81,87,98,155)$. In a mouse model of sepsis-induced ALI, blocking HMGB1 or myeloid-specific PTEN KO (PTEN MKO) increased TGF- $\beta$ production, inhibited Ror $\gamma$ t and IL-17 expression, and promoted the $\beta$-catenin signalling pathway. The increased CD4+CD25+Foxp3+ Tregs in the lungs improved survival and weight outcomes. However, the opposite result was obtained with myeloid-specific $\beta$-catenin ablation ( $\beta$ catenin $\mathrm{M}-\mathrm{KO})$. Furthermore, in vitro, the destruction of macrophage HMGB1/PTEN or activation of $\beta$-catenin significantly increased CD4+CD25+Foxp3+ Tregs (87). This also suggests that infiltration of macrophages could inhibit lung tissue-specific CD4+CD25+Foxp3+ Tregs via HMGB1/ $\mathrm{PTEN} / \beta$-catenin axis in sepsis-induced ALI.

The pathophysiology of sepsis-associated encephalopathy (SAE) is complex, multifactorial, and tissue-specific. Combining intertwined processes, SAE is promoted by countless alterations and dysfunctions resulting from the early and late stages of sepsis. Additionally, some patients experience chronic "sepsis brain" after sepsis recovery, such as inflammation, neuro-inflammation, oxidative stress, reduced 
brain metabolism, and injuries to the integrity of the blood brain barrier $(\mathrm{BBB})(84,156,157)$. In the early stage of sepsis, some corresponding interventions are effective in alleviating the uncontrolled hyper-inflammatory (IL-1 $\beta$, IL-6 IL-18, and TNF$\alpha$, etc.) and immune (CD3+CD4+ cells and CD3+CD8+ cells, etc.) responses associated with altering the $\mathrm{BBB}$ and amplifying the inflammatory responses of SAE (116, 156-158). Mesenchymal Stem Cell (MSC)-derived exosomes significantly increased the percentage and absolute number of Tregs, which ameliorated brain injury in the early stage of sepsis by mitigating the hyper-inflammatory and immune responses (116). As sepsis management techniques continue to improve, SAE is characterized as chronic "sepsis brain", which is associated with long-lasting cognitive deficits and psychological impairments such as anxiety and depression $(159,160)$. Using a CS-induced sepsis mouse model and focusing on chronic "sepsis brain", Saito et al. demonstrated that infiltrated Tregs and Th2 cells attenuate SAE and alleviate SAE-induced mental disorders by resolving neuroinflammation in the chronic phase of sepsis (84).

\section{PATHOGEN-SPECIFIC TREG PATTERNS IN SEPSIS}

Many previous induced sepsis models focused on Gram-negative bacteria and their products, such as LPS (50, 51, 101, 103, 118, 121, 161). A recent experimental LPS-induced endotoxemia study in humans showed that pro-inflammatory Th1 (IFN- $\gamma$, IL-2, and TNF $\alpha$ ) and Th17 (IL-17A) cells were suppressed, while the Tregs and their ability to produce anti-inflammatory IL-10 were not affected (162). In addition, glycolipids and diacylglycerols from Streptococcus pneumoniae, which cause high mortality in patients over 65-years-old, induced septic shock by activating invariant natural killer $\mathrm{T}$ cells (iNKT) and the hyper-inflammatory responses $(66,110,163,164)$. Tregs reduced the proliferation of iNKT and IL-4 secretion of iNKT induced by glycolipids (including bacterial-derived diacylglycerols). One striking observation was that Tregs significantly increased Foxp3 expression, inhibitory function, and IL-10 secretion after they contacted iNKT, especially in the presence of bacterial diacylglycerols (164). Recent evidence suggests that Streptococcus pneumoniae (including its components and live attenuated mutants) and pneumococcal infection may induce Treg proliferation and may be used in the treatment of asthma (165).

Graphene oxide (GO) is a single-atomic layered material composed of carbon with a variety of biomedical applications, such as gene delivery, stem cell differentiation, and cancer therapy (166). In addition, GO has been shown to be able to regulate innate and adaptive immune functions $(92,166,167)$. In vivo, the administration of GO significantly improved diacylglycerols-induced septic shock and inhibited the capacity of diacylglycerols to induce iNKT-mediated trans-activation and cytokine production of innate and innate-like cells (such as dendritic cells, macrophages, and $\gamma \delta \mathrm{T}$ cells), which were associated with the ability to increase the amount of Foxp3+ Tregs via TGF- $\beta$ (166). This shows that gut microbiota not only influences the gastrointestinal tract, but also supports immune cells in distal organ sites (168). In another example, dietary supplementation with nonfermentable fiber or high fiber (HF) cellulose altered the gut microbiota and positively impacted metabolic health to confer protection in sepsis models (109, 169). Supplementation with HF amplified the suppressive function of CD4+CD25+Foxp3+ Tregs, inhibited SIRS, and induced anergy in CD4+ $\mathrm{T}$ cells as compared to mice on a regular diet (109). These pieces of evidence also suggest that manipulating intestinal microbiota through dietary supplementation with fiber may have broader systemic effects on immune homeostasis by influencing the heterogeneity of CD4+CD25+Foxp3+ Tregs.

Fungi are involved in 20\% of sepsis and Candida is the most commonly isolated pathogen $(170,171)$. Patients with malignancies and immunodeficiencies are more likely to develop Candida albicans infection that leads to candidiasis (171). C. albicans induces the production of tumor infiltrating and IL-10 producing Tregs through toll-like receptor (TLR) 2, which leads to immune escape $(64,172)$. Different degrees (such as 1,3- $\beta$-D-glucan -positive colonization and invasive candidiasis) of Candida have different effects on patients with abdominal sepsis. Decreased B and NK cell counts, and reduced IL-8 secretion appeared to be associated with a higher risk of subsequent candidiasis, rather than the heterogeneous characteristics of Tregs. In contrast, the risk stratification of candidiasis did not affect the heterogeneous characteristics of Tregs in patients with abdominal sepsis (173).

\section{TIME-DEPENDENT TREG PATTERNS IN SEPSIS}

Considering the various failures of clinical trials targeting hyperinflammatory mediators (especially IL- $1 \beta$ and TNF- $\alpha$ ) and the fact that most septic patients who survive the acute stage of hyper-immune and inflammatory responses are burdened by secondary infections, it is necessary to perform basic and translational studies to understand the long-term post-sepsis immune perturbations $(26,27,45,46)$. The heterogeneous characteristics of Tregs are constantly changing over the course of sepsis. In the early stage of sepsis there is no difference in the percentage of Tregs in total CD4+ T cells between future sepsis survivors and non-survivors. However, non-survivors had a lower absolute number of Tregs compared to survivors. At the later stage of sepsis (after 3 days), the absolute number of Tregs increased, while the percentage of Tregs decreased in survivors. Although the absolute number of Tregs increased, the percentage of Tregs progressively increased in non-survivors. Moreover, survivors had a lower percentage of Tregs and a higher absolute number of Tregs $(69,75,138)$. During the early stage of sepsis, especially with organs injuries caused by hyper-inflammatory responses (such as ALI, AKI, ALF, etc.), increasing the proportion and absolute number of Tregs is critical to restore 
immune-inflammatory homeostasis, and reduce tissue damage and organs injury. Animals depleted of Tregs at this stage are unable to resolve SIRS and die from extensive tissue damage and MODS (20, 21, 70, 81, 98, 104, 108, 174).

Evidence from gene knock-out (KO) mice with sepsis induced by LPS or CLP illustrates that Tregs play a crucial role in inhibiting SIRS and ameliorating acute organs injury in the early stage of sepsis $(77-79,87,94)$. Gpr174 deficiency in Tregs promoted the expression of CTLA- 4 and the secretion of IL-10 in CD4+CD25+Foxp3+Tregs but the expression and percentage of PD-1 and Foxp3 was not affected. In Gpr174-KO mice induced by LPS or CLP to simulate sepsis, the induction of M2 macrophages in the early stage was Treg dependent and Gpr174-deficient Tregs protected mice from sepsis-induced ALI and improved survival by promoting M2 macrophage polarization (79).

The peritoneal contamination and infection (PCI) mouse model, which is consistent with secondary infections in postseptic patients, induced an increase in Bregs but did not induce a lasting increase in Treg absolute number in the spleens from 1 week to 3.5 months after sepsis induction (97). Since the absolute number of Foxp3+ Tregs in the lung tissues of CLP-induced septic mice increased nearly two-fold on the third day and returned to normal levels on the seventh day, mice were susceptible to intratracheal injection of Pseudomonas aeruginosa for 3 days, but not for 7 days (90). This suggests that Tregs have different functions at different stages of sepsis and contribute to secondary $P$. aeruginosa infection. In a study with Xuebijing Injection, which contains 5 Chinese medicine herbal extracts, mice were injected once/day for 5 days after CLP. Septic mice had significantly improved 7-day survival and reduced acute organ injury, which is associated with stimulated IL-10+ Foxp3+ Tregs, inhibited Th17 differentiation, and decreased Th17/Tregs (104). Some TCM, such as rhubarb, have a bidirectional regulatory effect on the heterogeneity of Tregs over time and improve the prognosis of sepsis by increasing the proportion of Tregs in the early stage and decreasing it in the late stage, although the specific molecular mechanism of their effect is not clear (100). Although these results are contradictory, they do imply that Foxp3+ Tregs play an important role in amending early, late, and even long-term immune disturbances after sepsis.

\section{LIMITATIONS OF TREG MODELS IN SEPSIS}

While most of the data discussed in this review comes from animal models, their limitations must be acknowledged. Most previous experiments related to sepsis were induced by CLP or LPS, where researchers used inbred mice under a specific pathogen-free (SPF) experimental environment. These methods do not fully conform to clinical heterogeneity and often do not inform the treatment of sepsis in humans $(50,51$, $101,103,118,121,161,175)$. In fact, changes in the heterogeneity of Tregs in induced sepsis animal models do not fully reflect clinical sepsis or are even opposite to patients' results $(51,75)$. Although LPS induction is a frequently used sepsis model, mice and other rodents are much less sensitive to LPS than humans. Thus, a 106 times higher $(1-25 \mathrm{mg} / \mathrm{kg})$ dose is required for mice compared to humans, who only need $2-4 \mathrm{ng} / \mathrm{kg}$ to induce SIRS $(124,162,176)$. Furthermore, in most current experiments using LPS, the regimens and dosages of LPS vary widely among different mouse strains, animal ages, and animal facilities (23, $70,87,98,109,117,118)$. For example, BALB/c mice induced by intraperitoneal injection of LPS $(0.2 \mu \mathrm{g} / \mathrm{g}$ of body weight or $5 \mu \mathrm{g} /$ mouse per day) for 5 consecutive days, showed significant decreases of CD4+, CD8+, CD3z+, and CD19+ cells and an increase of the percentage of CD25+Foxp3+ Tregs, accompanied with increased production of IL- 6 , TNF- $\alpha$, and IL-18 in the serum. These results are consistent with the co-existence of SIRS and CARS observed in the early stage of septic patients $(4,15,26$, $45-51,118)$. In a cross-design placebo-controlled study of 20 healthy male volunteers who received intravenous LPS $(0.8 \mathrm{ng} / \mathrm{kg}$ body weight), their circulating neutrophils significantly increased. Additionally, the absolute numbers of CD3+, CD4+, and CD8+ T cells decreased 2 hours after LPS injection. In contrast, the frequency of Tregs and their ability to produce IL10 did not change (162).

In the CLP model, the cecum of immunocompetent mice is sutured and then punctured to cause spillage of cecal contents into the peritoneum, which creates a life-threatening infection characterized by physical disorders (such as septic shock and acute organ failure) and ultimately death (99, 106, 161). Unfortunately, the precise composition of cecal contents that participates in the infection process is variable and has not been adequately evaluated in the case of acute organ failure (175). To compensate, some investigators tried to adopt intraperitoneal injection of stool suspension or CS, or endotracheal injection of a predetermined pathogen (such as Klebsiella pneumonia and Staphylococcus aureus, etc.) $(59,67,97)$. The "two-hit" model was used to mimic clinical conditions of secondary infection, but different regimens yielded surprisingly different results $(57,70$, 83, 90, 97).

Due to their relatively stable genetic uniformity, inbred $\mathrm{BALB} / \mathrm{c}$ and $\mathrm{C} 57 \mathrm{BL} / 6$ mice are most frequently used in sepsisrelated studies $(47,59,65,70,83,86,98,118,177)$. Nevertheless, researchers are beginning to emphasize the importance of using genetically heterogeneous organisms in experiments since they can better simulate the heterozygosity of humans, especially in multi-dimensional heterogeneous syndromes such as sepsis (19, $23,67,85,100,135,136)$. BALB/c (inbred) and CD-1 (outbred) mice underwent unilateral femoral fracture, splenectomy, and hemorrhagic shock, with increased circulating granulocytes (LY6G+CD11+) in both strains at 24 and 48 hours later. However, CD8+ T cells decreased by $30 \%$ within $48 \mathrm{~h}$ only in $\mathrm{BALB} / \mathrm{c}$ mice. Circulating CD4+CD25+CD127low Tregs and lymphocytes (CD11B-LY6G-MHC-2+) were always at least 1.5-fold higher in $\mathrm{BALB} / \mathrm{c}$ mice, while $\mathrm{MHC}-2$ expression in bone marrow decreased in CD-1 mice. In addition, $\mathrm{BALB} / \mathrm{c}$ mice expressed higher levels of circulatory CD4+CD25+CD127low Tregs and MHC-2+ lymphocytes, compared to CD-1 mice (178). 
Based on the high heterogeneity of Tregs observed in clinical sepsis patient samples, we suggest that sepsis animal models should be designed to mimic this heterogeneity. For example, new sepsis models could be designed by guidance from both clinical sepsis patient characteristic and Treg immune checkpoints. Some experimental models of sepsis such as the "memory mouse" (57, 95), "two- or three-hit mouse" $(70,118)$, and "gene recombination mouse" models $(78,79,94)$ have begun to move the field closer to more relevant sepsis models.

\section{THERAPEUTIC INTERVENTIONS TARGETING TREGS}

Several lines of evidence from experimental studies suggest that Tregs can be the target for therapeutic interventions. Deletion of Treg Notch4 gene with anti-Notch4 immunization in rodents normalizes dysregulated innate immunity to reduce morbidity and mortality (179). Lymphocyte-deficient recombinase activating gene-1 knockout mice exhibit impairments in lung injury healing. It has been found that administering isolated Tregs in a model of lung injury helps improve recovery (180). Depletion of Foxp3-positive Tregs from proliferating alveolar cells in a rodent model led to a decrease in epithelial proliferation (181). Such observations suggest that there are several pathways to explore regarding the therapeutic role of Tregs in sepsis. Moreover, Th17/Treg ratio alterations in favor of Th17 also have implications for therapeutic utility for lung injury and acute respiratory distress syndrome $(182,183)$.

\section{DISCUSSION}

Sepsis remains the leading cause of death in ICUs due to the progress of aging, numerous chronic comorbidities (diabetes, malignancies, autoimmune diseases, etc.), multi-drug resistant bacterial pathogens caused by excessive use of antibiotics, repeated secondary infections and other factors. The main pathologic mechanism of sepsis-induced immunosuppression is not completely understood. Furthermore, systematic, standardized clinical treatment for sepsis-induced immunosuppression is lacking. Therefore, there is an urgent

\section{REFERENCES}

1. Rudd KE, Johnson SC, Agesa KM, Shackelford KA, Tsoi D, Kievlan DR, et al. Global, Regional, and National Sepsis Incidence and Mortality, 19902017: Analysis for the Global Burden of Disease Study. Lancet (2020) 395 (10219):200-11. doi: 10.1016/S0140-6736(19)32989-7

2. Xie J, Wang H, Kang Y, Zhou L, Liu Z, Qin B, et al. The Epidemiology of Sepsis in Chinese ICUs: A National Cross-Sectional Survey. Crit Care Med (2020) 48(3):e209-e18. doi: 10.1097/CCM.0000000000004155

3. Weng L, Zeng XY, Yin P, Wang LJ, Wang CY, Jiang W, et al. Sepsis-Related Mortality in China: A Descriptive Analysis. Intensive Care Med (2018) 44 (7):1071-80. doi: 10.1007/s00134-018-5203-Z

4. Rhodes A, Evans LE, Alhazzani W, Levy MM, Antonelli M, Ferrer R, et al. Surviving Sepsis Campaign: International Guidelines for Management of need for a better understanding of the pathophysiological mechanisms of sepsis. New approaches to identify biological targets and checkpoints for detection, assessment, and management must be developed. Research that is emerging from the study of COVID-19 is likely to further inform scientists about the roles of Tregs in sepsis. In COVID-19 patients, Tregs are reported to behave variably. Whereas some studies have reported decreases in Tregs in COVID-19 patients $(184,185)$, others have reported increases in Tregs in COVID-19 patients $(186,187)$. An imbalance in the Treg/Th17 ratio in COVID-19 patients may increase the risk of respiratory failure $(74,188)$. Overall, to improve sepsis symptoms through the regulation of Tregs, it is necessary to find the optimal balance point for Tregs to play a role in sepsis. Researchers should not only take into account the heterogeneous characteristics of Tregs, but also the characteristics and organ/tissue-specific patterns of the host, the multi-dimensional heterogeneous syndrome of sepsis, the different types of pathogenic organisms, and even different types of laboratory research models and clinical research methods.

\section{AUTHOR CONTRIBUTIONS}

Conceptualization, Y-lG, YY, and Y-fC. Writing-original draft preparation, Y-lG, YY, XZ, FC, X-lM, X-sC, C-lW, and Y-cL. Writing-review and editing, $\mathrm{Y}-\mathrm{lG}, \mathrm{Y}-\mathrm{fC}$, and $\mathrm{XT}$. Supervision, S-tS, Y-fC, and Y-lG. Funding acquisition, Y-lG and Y-fC. All authors have read and agreed to the published version of the manuscript.

\section{FUNDING}

This work was supported by the National Natural Science Foundation of China (No. 81871593, 81701931), and the National Natural Science Foundation of Tianjin (No. 18JCQNJC10500).

\section{ACKNOWLEDGMENTS}

We thank prof. Shu-Zhang Cui of Tianjin Medical University General Hospital for the help with the experimental design.
Sepsis and Septic Shock: 2016. Intensive Care Med (2017) 43(3):304-77. doi: 10.1007/s00134-017-4683-6

5. Weiss SL, Peters MJ, Alhazzani W, Agus MSD, Flori HR, Inwald DP, et al. Surviving Sepsis Campaign International Guidelines for the Management of Septic Shock and Sepsis-Associated Organ Dysfunction in Children. Pediatr Crit Care Med (2020) 21(2):e52-106. doi: 10.1097/PCC.0000000000002198

6. Karakike E, Kyriazopoulou E, Tsangaris I, Routsi C, Vincent JL, GiamarellosBourboulis EJ. The Early Change of SOFA Score as a Prognostic Marker of 28-Day Sepsis Mortality: Analysis Through a Derivation and a Validation Cohort. Crit Care (2019) 23(1):387. doi: 10.1186/s13054-019-2665-5

7. De Waele JJ, Akova M, Antonelli M, Canton R, Carlet J, De Backer D, et al. Antimicrobial Resistance and Antibiotic Stewardship Programs in the ICU: Insistence and Persistence in the Fight Against Resistance. A Position Statement From ESICM/ESCMID/WAAAR Round Table on Multi-Drug 
Resistance. Intensive Care Med (2018) 44(2):189-96. doi: 10.1007/s00134017-5036-1

8. Klein L, Robey EA, Hsieh C-S. Central CD4+ T Cell Tolerance: Deletion Versus Regulatory T Cell Differentiation. Nat Rev Immunol (2018) 19(1):718. doi: 10.1038/s41577-018-0083-6

9. von Knethen A, Heinicke U, Weigert A, Zacharowski K, Brune B. Histone Deacetylation Inhibitors as Modulators of Regulatory T Cells. Int J Mol Sci (2020) 21(7):2356. doi: 10.3390/ijms21072356

10. Sakaguchi S, Toda M, Asano M, Itoh M, Morse SS, Sakaguchi N. T CellMediated Maintenance of Natural Self-Tolerance: Its Breakdown as a Possible Cause of Various Autoimmune Diseases. J Autoimmun (1996) 9 (2):211-20. doi: 10.1006/jaut.1996.0026

11. Ramsdell F, Rudensky AY. Foxp3: A Genetic Foundation for Regulatory T Cell Differentiation and Function. Nat Immunol (2020) 21(7):708-9. doi: 10.1038/s41590-020-0694-5

12. Cortez JT, Montauti E, Shifrut E, Gatchalian J, Zhang Y, Shaked O, et al. CRISPR Screen in Regulatory T Cells Reveals Modulators of Foxp3. Nature (2020) 582(7812):416-20. doi: 10.1038/s41586-020-2246-4

13. Tatura R, Zeschnigk M, Hansen W, Steinmann J, Vidigal PG, Hutzler M, et al. Relevance of Foxp3(+) Regulatory T Cells for Early and Late Phases of Murine Sepsis. Immunology (2015) 146(1):144-56. doi: 10.1111/imm.12490

14. Yao RQ, Ren C, Wang JN, Wu GS, Zhu XM, Xia ZF, et al. Publication Trends of Research on Sepsis and Host Immune Response During 19992019: A 20-Year Bibliometric Analysis. Int J Biol Sci (2020) 16(1):27-37. doi: 10.7150/ijbs. 37496

15. McBride MA, Patil TK, Bohannon JK, Hernandez A, Sherwood ER, Patil NK. Immune Checkpoints: Novel Therapeutic Targets to Attenuate SepsisInduced Immunosuppression. Front Immunol (2020) 11:624272. doi: 10.3389/fimmu.2020.624272

16. Poujol F, Monneret G, Gallet-Gorius E, Pachot A, Textoris J, Venet F. Ex Vivo Stimulation of Lymphocytes With IL-10 Mimics Sepsis-Induced Intrinsic T-Cell Alterations. Immunol Invest (2018) 47(2):154-68. doi: 10.1080/08820139.2017.1407786

17. George JA, Park SO, Choi JY, Uyangaa E, Eo SK. Double-Faced Implication of CD4(+) Foxp3(+) Regulatory T Cells Expanded by Acute Dengue Infection via TLR2/MyD88 Pathway. Eur J Immunol (2020) 50(7):100018. doi: 10.1002/eji.201948420

18. Ono S, Kimura A, Hiraki S, Takahata R, Tsujimoto H, Kinoshita M, et al. Removal of Increased Circulating CD4+CD25+Foxp3+ Regulatory T Cells in Patients With Septic Shock Using Hemoperfusion With Polymyxin BImmobilized Fibers. Surgery (2013) 153(2):262-71. doi: 10.1016/ j.surg.2012.06.023

19. Zou Q, Yang M, Yu M, Liu C. Influences of Regulation of miR-126 on Inflammation,Th17/Treg Subpopulation Differentiation, and Lymphocyte Apoptosis Through Caspase Signaling Pathway in Sepsis. Inflammation (2020) 43(6):2287-300. doi: 10.1007/s10753-020-01298-7

20. Xia H, Wang F, Wang M, Wang J, Sun S, Chen M, et al. Maresin1 Ameliorates Acute Lung Injury Induced by Sepsis Through Regulating Th17/Treg Balance. Life Sci (2020) 254:117773. doi: 10.1016/j.lfs.2020. 117773

21. Liu P, Xiao Z, Yan H, Lu X, Zhang X, Luo L, et al. Baicalin Suppresses Th1 and Th17 Responses and Promotes Treg Response to Ameliorate SepsisAssociated Pancreatic Injury via the RhoA-ROCK Pathway. Int Immunopharmacol (2020) 86:106685. doi: 10.1016/j.intimp.2020.106685

22. Sun JK, Zhang WH, Chen WX, Wang X, Mu XW. Effects of Early Enteral Nutrition on Th17/Treg Cells and IL-23/IL-17 in Septic Patients. World J Gastroenterol (2019) 25(22):2799-808. doi: 10.3748/wjg.v25.i22.2799

23. He W, Xiao K, Xu J, Guan W, Xie S, Wang K, et al. Recurrent Sepsis Exacerbates CD4(+) T Cell Exhaustion and Decreases Antiviral Immune Responses. Front Immunol (2021) 12:627435. doi: 10.3389/fimmu.2021. 627435

24. Coopersmith CM, De Backer D, Deutschman CS, Ferrer R, Lat I, Machado FR, et al. Surviving Sepsis Campaign: Research Priorities for Sepsis and Septic Shock. Intensive Care Med (2018) 44(9):1400-26. doi: 10.1007/ s00134-018-5175-z

25. Bone RC, Balk RA, Cerra FB, Dellinger RP, Fein AM, Knaus WA, et al. Definitions for Sepsis and Organ Failure and Guidelines for the Use of Innovative Therapies in Sepsis. The ACCP/SCCM Consensus Conference
Committee. American College of Chest Physicians/Society of Critical Care Medicine. Chest (1992) 101(6):1644-55. doi: 10.1378/chest.101.6.1644

26. Hotchkiss RS, Monneret G, Payen D. Sepsis-Induced Immunosuppression: From Cellular Dysfunctions to Immunotherapy. Nat Rev Immunol (2013) 13 (12):862-74. doi: 10.1038/nri3552

27. Poutsiaka DD, Porto MC, Perry WA, Hudcova J, Tybor DJ, Hadley S, et al. Prospective Observational Study Comparing Sepsis-2 and Sepsis-3 Definitions in Predicting Mortality in Critically Ill Patients. Open Forum Infect Dis (2019) 6(7):ofz271. doi: 10.1093/ofid/ofz271

28. Raith EP, Udy AA, Bailey M, McGloughlin S, MacIsaac C, Bellomo R, et al. Prognostic Accuracy of the SOFA Score, SIRS Criteria, and qSOFA Score for In-Hospital Mortality Among Adults With Suspected Infection Admitted to the Intensive Care Unit. JAMA (2017) 317(3):290-300. doi: 10.1001/ jama.2016.20328

29. Singer M, Deutschman CS, Seymour CW, Shankar-Hari M, Annane D, Bauer M, et al. The Third International Consensus Definitions for Sepsis and Septic Shock (Sepsis-3). JAMA (2016) 315(8):801-10. doi: 10.1001/ jama.2016.0287

30. Seymour CW, Liu VX, Iwashyna TJ, Brunkhorst FM, Rea TD, Scherag A, et al. Assessment of Clinical Criteria for Sepsis: For the Third International Consensus Definitions for Sepsis and Septic Shock (Sepsis-3). JAMA (2016) 315(8):762-74. doi: 10.1001/jama.2016.0288

31. Liu YC, Luo YY, Zhang X, Shou ST, Gao YL, Lu B, et al. Quick Sequential Organ Failure Assessment as a Prognostic Factor for Infected Patients Outside the Intensive Care Unit: A Systematic Review and Meta-Analysis. Intern Emerg Med (2019) 14(4):603-15. doi: 10.1007/s11739-019-02036-0

32. Evans L, Rhodes A, Alhazzani W, Antonelli M, Coopersmith CM, French C, et al. Surviving Sepsis Campaign: International Guidelines for Management of Sepsis and Septic Shock 2021. Crit Care Med (2021) 49(11):e1063-143. doi: 10.1097/CCM.0000000000005337

33. Kellum JA, Pike F, Yealy DM, Huang DT, Shapiro NI, Angus DC, et al Relationship Between Alternative Resuscitation Strategies, Host Response and Injury Biomarkers, and Outcome in Septic Shock: Analysis of the Protocol-Based Care for Early Septic Shock Study. Crit Care Med (2017) 45(3):438-45. doi: 10.1097/CCM.0000000000002206

34. Ono S, Tsujimoto H, Hiraki S, Aosasa S. Mechanisms of Sepsis-Induced Immunosuppression and Immunological Modification Therapies for Sepsis. Ann Gastroenterol Surg (2018) 2(5):351-8. doi: 10.1002/ags3.12194

35. Schmoeckel K, Mrochen DM, Huhn J, Potschke C, Broker BM Polymicrobial Sepsis and Non-Specific Immunization Induce Adaptive Immunosuppression to a Similar Degree. PloS One (2018) 13(2):e0192197. doi: 10.1371/journal.pone.0192197

36. Hotchkiss RS, Karl IE. The Pathophysiology and Treatment of Sepsis. N Engl $J$ Med (2003) 348(2):138-50. doi: 10.1056/NEJMra021333

37. Carvelli J, Piperoglou C, Bourenne J, Farnarier C, Banzet N, Demerle C, et al. Imbalance of Circulating Innate Lymphoid Cell Subpopulations in Patients With Septic Shock. Front Immunol (2019) 10:2179. doi: 10.3389/ fimmu.2019.02179

38. Rhee C, Dantes R, Epstein L, Murphy DJ, Seymour CW, Iwashyna TJ, et al. Incidence and Trends of Sepsis in US Hospitals Using Clinical vs Claims Data, 2009-2014. JAMA (2017) 318(13):1241-9. doi: 10.1001/ jama.2017.13836

39. Seymour CW, Gesten F, Prescott HC, Friedrich ME, Iwashyna TJ, Phillips GS, et al. Time to Treatment and Mortality During Mandated Emergency Care for Sepsis. N Engl J Med (2017) 376(23):2235-44. doi: 10.1056/ NEJMoa1703058

40. Lu Y, An L, Liu Q, Li C. Expression and Clinical Correlations of Costimulatory Molecules on Peripheral T Lymphocyte Subsets of EarlyStage Severe Sepsis: A Prospective Observational Study. Shock (2018) 49 (6):631-40. doi: 10.1097/SHK.0000000000001017

41. You B, Zhang YL, Luo GX, Dang YM, Jiang B, Huang GT, et al. Early Application of Continuous High-Volume Haemofiltration can Reduce Sepsis and Improve the Prognosis of Patients With Severe Burns. Crit Care (2018) 22(1):173. doi: 10.1186/s13054-018-2095-9

42. Liu Y, Zhao W, Chen W, Shen X, Fu R, Zhao Y, et al. Effects of Early Enteral Nutrition on Immune Function and Prognosis of Patients With Sepsis on Mechanical Ventilation. J Intensive Care Med (2020) 35(10):1053-61. doi $10.1177 / 0885066618809893$ 
43. Yang XY, Song J, Hou SK, Fan HJ, Lv Q, Liu ZQ, et al. Ulinastatin Ameliorates Acute Kidney Injury Induced by Crush Syndrome Inflammation by Modulating Th17/Treg Cells. Int Immunopharmacol (2020) 81:106265. doi: 10.1016/j.intimp.2020.106265

44. Antonakos N, Tsaganos T, Oberle V, Tsangaris I, Lada M, Pistiki A, et al. Decreased Cytokine Production by Mononuclear Cells After Severe GramNegative Infections: Early Clinical Signs and Association With Final Outcome. Crit Care (2017) 21(1):48. doi: 10.1186/s13054-017-1625-1

45. Donnelly JP, Hohmann SF, Wang HE. Unplanned Readmissions After Hospitalization for Severe Sepsis at Academic Medical Center-Affiliated Hospitals. Crit Care Med (2015) 43(9):1916-27. doi: 10.1097/ CCM.0000000000001147

46. Hotchkiss RS, Colston E, Yende S, Crouser ED, Martin GS, Albertson T, et al. Immune Checkpoint Inhibition in Sepsis: A Phase 1b Randomized Study to Evaluate the Safety, Tolerability, Pharmacokinetics, and Pharmacodynamics of Nivolumab. Intensive Care Med (2019) 45 (10):1360-71. doi: 10.1007/s00134-019-05704-z

47. Gao Y, Li L, Liu Y, Li W, Wang Z, Shou S, et al. [Effect of Semaphorin-3A on the Cellular Stability of CD4(+)CD25(+) Regulatory T Cells Induced by Lipopolysaccharide]. Zhonghua Wei Zhong Bing Ji Jiu Yi Xиe (2020) 32 (12):1454-60. doi: 10.3760/cma.j.cn121430-20200706-00501

48. Gao Y, Wang C, Wang Z, Li W, Liu Y, Shou S, et al. Semaphorin 3A Contributes to Sepsis-Induced Immunosuppression by Impairing CD4+ T Cell Anergy. Mol Med Rep (2021) 23(4):302. doi: 10.3892/mmr.2021.11941

49. von Dach E, Albrich WC, Brunel A-S, Prendki V, Cuvelier C, Flury D, et al. Effect of C-Reactive Protein-Guided Antibiotic Treatment Duration, 7-Day Treatment, or 14-Day Treatment on 30-Day Clinical Failure Rate in Patients With Uncomplicated Gram-Negative Bacteremia. JAMA (2020) 323 (21):2160-9. doi: 10.1001/jama.2020.6348

50. Gao Y-L, Wang C-X, Wang Z-Y, Li W-J, Liu Y-C, Shou S-T, et al. Targeting Neuropilin-1 Suppresses the Stability of CD4 CD25 Regulatory T Cells via the NF-kb Signaling Pathway in Sepsis. Infect Immun (2021) 89(2):e0039920. doi: 10.1128/IAI.00399-20

51. Martin AN, Alexander-Miller M, Yoza BK, Vachharajani V, McCall CE. Sirtuin1 Targeting Reverses Innate and Adaptive Immune Tolerance in Septic Mice. J Immunol Res (2018) 2018:2402593. doi: 10.1155/2018/ 2402593

52. Daviaud F, Grimaldi D, Dechartres A, Charpentier J, Geri G, Marin N, et al. Timing and Causes of Death in Septic Shock. Ann Intensive Care (2015) 5 (1):16. doi: 10.1186/s13613-015-0058-8

53. Olonisakin TF, Suber T, Gonzalez-Ferrer S, Xiong Z, Peñaloza HF, van der Geest R, et al. Stressed Erythrophagocytosis Induces Immunosuppression During Sepsis Through Heme-Mediated STAT1 Dysregulation. J Clin Invest (2021) 131(1):e137468. doi: 10.1172/JCI137468

54. Zhang H, Xu CF, Ren C, Wu TT, Dong N, Yao YM. Novel Role of P53 in Septic Immunosuppression: Involvement in Loss and Dysfunction of CD4+ T Lymphocytes. Cell Physiol Biochem (2018) 51(1):452-69. doi: 10.1159/ 000495241

55. Chen CW, Xue M, Zhang W, Xie J, Coopersmith CM, Ford ML. 2B4 But Not PD-1 Blockade Improves Mortality in Septic Animals With Preexisting Malignancy. JCI Insight (2019) 4(22):e127867. doi: 10.1172/ jci.insight. 127867

56. Chen C-W, Mittal R, Klingensmith NJ, Burd EM, Terhorst C, Martin GS, et al. Cutting Edge: 2b4-Mediated Coinhibition of CD4+ T Cells Underlies Mortality in Experimental Sepsis. J Immunol (2017) 199(6):1961-6. doi: 10.4049/jimmunol.1700375

57. Sun Y, Anyalebechi JC, Sun H, Yumoto T, Xue M, Liu D, et al. Anti-TIGIT Differentially Affects Sepsis Survival in Immunologically Experienced Versus Previously Naive Hosts. JCI Insight (2021) 6(5):e141245. doi: 10.1172/ jci.insight. 141245

58. Chang KC, Burnham C-A, Compton SM, Rasche DP, Mazuski RJ, McDonough JS, et al. Blockade of the Negative Co-Stimulatory Molecules PD-1 and CTLA-4 Improves Survival in Primary and Secondary Fungal Sepsis. Crit Care (London England) (2013) 17(3):R85. doi: 10.1186/cc12711

59. Saito M, Inoue S, Yamashita K, Kakeji Y, Fukumoto T, Kotani J. IL-15 Improves Aging-Induced Persistent T Cell Exhaustion in Mouse Models of Repeated Sepsis. Shock (2020) 53(2):228-35. doi: 10.1097/ SHK.0000000000001352
60. Xu J, Li J, Xiao K, Zou S, Yan P, Xie X, et al. Dynamic Changes in Human HLA-DRA Gene Expression and Th Cell Subsets in Sepsis: Indications of Immunosuppression and Associated Outcomes. Scand J Immunol (2020) 91 (1):e12813. doi: 10.1111/sji.12813

61. Landelle C, Lepape A, Voirin N, Tognet E, Venet F, Bohe J, et al. Low Monocyte Human Leukocyte Antigen-DR is Independently Associated With Nosocomial Infections After Septic Shock. Intensive Care Med (2010) 36 (11):1859-66. doi: 10.1007/s00134-010-1962-x

62. Yende S, Kellum JA, Talisa VB, Peck Palmer OM, Chang CH, Filbin MR, et al. Long-Term Host Immune Response Trajectories Among Hospitalized Patients With Sepsis. JAMA Netw Open (2019) 2(8):e198686. doi: 10.1001/ jamanetworkopen.2019.8686

63. Franekova J, Protus M, Kieslichova E, Brezina A, Komrskova J, Vymetalik J, et al. Changes in Sepsis Biomarkers After Immunosuppressant Administration in Transplant Patients. Mediators Inflammation (2021) 2021:8831659. doi: 10.1155/2021/8831659

64. Ahmadi N, Ahmadi A, Kheirali E, Hossein Yadegari M, Bayat M, Shajiei A, et al. Systemic Infection With Candida Albicans in Breast Tumor Bearing Mice: Cytokines Dysregulation and Induction of Regulatory T Cells. J Mycol Med (2019) 29(1):49-55. doi: 10.1016/j.mycmed.2018.10.006

65. Drechsler S, Zipperle J, Rademann P, Jafarmadar M, Klotz A, Bahrami S, et al. Splenectomy Modulates Early Immuno-Inflammatory Responses to Trauma-Hemorrhage and Protects Mice Against Secondary Sepsis. Sci Rep (2018) 8(1):14890. doi: 10.1038/s41598-018-33232-1

66. Wester AL, Dunlop O, Melby KK, Dahle UR, Wyller TB. Age-Related Differences in Symptoms, Diagnosis and Prognosis of Bacteremia. BMC Infect Dis (2013) 13:346. doi: 10.1186/1471-2334-13-346

67. Li L-L, Dai B, Sun Y-H, Zhang T-T. The Activation of IL-17 Signaling Pathway Promotes Pyroptosis in Pneumonia-Induced Sepsis. Ann Trans Med (2020) 8(11):674-. doi: 10.21037/atm-19-1739

68. de Roquetaillade C, Mansouri S, Brumpt C, Neuwirth M, Voicu S, Le Dorze $\mathrm{M}$, et al. Comparison of Circulating Immune Cells Profiles and Kinetics Between Coronavirus Disease 2019 and Bacterial Sepsis. Crit Care Med (2021) 49(10):1717-25. doi: 10.1097/CCM.0000000000005088

69. Bomans K, Schenz J, Sztwiertnia I, Schaack D, Weigand MA, Uhle F. Sepsis Induces a Long-Lasting State of Trained Immunity in Bone Marrow Monocytes. Front Immunol (2018) 9:2685. doi: 10.3389/fimmu.2018.02685

70. Tran DT, Jeong YY, Kim JM, Bae HB, Son SK, Kwak SH. The AntiInflammatory Role of Bilirubin on "Two-Hit" Sepsis Animal Model. Int $J$ Mol Sci (2020) 21(22):8650. doi: 10.3390/ijms21228650

71. Luo CT, Li MO. Transcriptional Control of Regulatory T Cell Development and Function. Trends Immunol (2013) 34(11):531-9. doi: 10.1016/ j.it.2013.08.003

72. Zemmour D, Zilionis R, Kiner E, Klein AM, Mathis D, Benoist C. Single-Cell Gene Expression Reveals a Landscape of Regulatory T Cell Phenotypes Shaped by the TCR. Nat Immunol (2018) 19(3):291-301. doi: 10.1038/ s41590-018-0051-0

73. Wing JB, Tanaka A, Sakaguchi S. Human FOXP3(+) Regulatory T Cell Heterogeneity and Function in Autoimmunity and Cancer. Immunity (2019) 50(2):302-16. doi: 10.1016/j.immuni.2019.01.020

74. Yin F, Xi YL, Wang Y, Li BR, Qian J, Ren H, et al. The Clinical Outcomes and Biomarker Features of Severe Sepsis/Septic Shock With Severe Neutropenia: A Retrospective Cohort Study. Transl Pediatr (2021) 10(3):464-73. doi: $10.21037 / \mathrm{tp}-20-230$

75. Liu Q, Lu Y, An L, Li CS. B- and T-Lymphocyte Attenuator Expression on Regulatory T-Cells in Patients With Severe Sepsis. Chin Med J (Engl) (2018) 131(21):2637-9. doi: 10.4103/0366-6999.244104

76. Jiang W, Li X, Ding H, Wang K, Liu X, Wang Q, et al. PD-1 in Tregs Predicts the Survival in Sepsis Patients Using Sepsis-3 Criteria: A Prospective, TwoStage Study. Int Immunopharmacol (2020) 89(Pt A):107175. doi: 10.1016/ j.intimp.2020.107175

77. Lou JS, Wang JF, Fei MM, Zhang Y, Wang J, Guo Y, et al. Targeting Lymphocyte Activation Gene 3 to Reverse T-Lymphocyte Dysfunction and Improve Survival in Murine Polymicrobial Sepsis. J Infect Dis (2020) 222 (6):1051-61. doi: 10.1093/infdis/jiaa191

78. Fay KT, Chihade DB, Chen CW, Klingensmith NJ, Lyons JD, Ramonell K, et al. Increased Mortality in CD43-Deficient Mice During Sepsis. PloS One (2018) 13(9):e0202656. doi: 10.1371/journal.pone.0202656 
79. Qiu D, Chu X, Hua L, Yang Y, Li K, Han Y, et al. Gpr174-Deficient Regulatory T Cells Decrease Cytokine Storm in Septic Mice. Cell Death Dis (2019) 10(3):233. doi: 10.1038/s41419-019-1462-z

80. Yu Q, Li Y, Wang H, Xiong H. TSLP Induces a Proinflammatory Phenotype in Circulating Innate Cells and Predicts Prognosis in Sepsis Patients. FEBS Open Bio (2019) 9(12):2137-48. doi: 10.1002/2211-5463.12746

81. Zhao J, Liu Y, Hu JN, Peng M, Dong N, Zhu XM, et al. Autocrine Regulation of Interleukin-3 in the Activity of Regulatory T Cells and its Effectiveness in the Pathophysiology of Sepsis. J Infect Dis (2021) 223(5):893-904. doi: 10.1093/infdis/jiaa441

82. Xu T, Zhao J, Wang X, Meng Y, Zhao Z, Bao R, et al. CXCL4 Promoted the Production of CD4(+)CD25(+)FOXP3(+)treg Cells in Mouse Sepsis Model Through Regulating STAT5/FOXP3 Pathway. Autoimmunity (2020) 53 (5):289-96. doi: 10.1080/08916934.2020.1777283

83. Gaborit BJ, Roquilly A, Louvet C, Sadek A, Tessoulin B, Broquet A, et al. Regulatory T Cells Expressing Tumor Necrosis Factor Receptor Type 2 Play a Major Role in CD4+ T-Cell Impairment During Sepsis. J Infect Dis (2020) 222(7):1222-34. doi: 10.1093/infdis/jiaa225

84. Saito M, Fujinami Y, Ono Y, Ohyama S, Fujioka K, Yamashita K, et al. Infiltrated Regulatory T Cells and Th2 Cells in the Brain Contribute to Attenuation of Sepsis-Associated Encephalopathy and Alleviation of Mental Impairments in Mice With Polymicrobial Sepsis. Brain Behav Immun (2021) 92:25-38. doi: 10.1016/j.bbi.2020.11.010

85. Baek O, Ren S, Brunse A, Sangild PT, Nguyen DN. Impaired Neonatal Immunity and Infection Resistance Following Fetal Growth Restriction in Preterm Pigs. Front Immunol (2020) 11:1808. doi: 10.3389/fimmu.2020.01808

86. Shrestha AK, Bettini ML, Menon RT, Gopal VYN, Huang S, Edwards DP, et al. Consequences of Early Postnatal Lipopolysaccharide Exposure on Developing Lungs in Mice. Am J Physiol Lung Cell Mol Physiol (2019) 316 (1):L229-L44. doi: 10.1152/ajplung.00560.2017

87. Zhou M, Fang H, Du M, Li C, Tang R, Liu H, et al. The Modulation of Regulatory T Cells via HMGB1/PTEN/beta-Catenin Axis in LPS Induced Acute Lung Injury. Front Immunol (2019) 10:1612. doi: 10.3389/ fimmu.2019.01612

88. Andrade MMC, Ariga SSK, Barbeiro DF, Barbeiro HV, Pimentel RN, Petroni RC, et al. Endotoxin Tolerance Modulates TREG and TH17 Lymphocytes Protecting Septic Mice. Oncotarget (2019) 10(37):3451-61. doi: 10.18632/oncotarget.26919

89. Cao C, Chai Y, Shou S, Wang J, Huang Y, Ma T. Toll-Like Receptor 4 Deficiency Increases Resistance in Sepsis-Induced Immune Dysfunction. Int Immunopharmacol (2018) 54:169-76. doi: 10.1016/j.intimp.2017.11.006

90. Hu ZQ, Yao YM, Chen W, Bian JL, Zhao LJ, Chen LW, et al. Partial Depletion of Regulatory T Cells Enhances Host Inflammatory Response Against Acute Pseudomonas Aeruginosa Infection After Sepsis. Inflammation (2018) 41(5):1780-90. doi: 10.1007/s10753-018-0821-8

91. Greenberg JA, Hohmann SF, Hall JB, Kress JP, David MZ. Validation of a Method to Identify Immunocompromised Patients With Severe Sepsis in Administrative Databases. Ann Am Thorac Soc (2016) 13(2):253-8. doi: 10.1513/AnnalsATS.201507-415BC

92. Shurin MR, Yanamala N, Kisin ER, Tkach AV, Shurin GV, Murray AR, et al. Graphene Oxide Attenuates Th2-Type Immune Responses, But Augments Airway Remodeling and Hyperresponsiveness in a Murine Model of Asthma. ACS Nano (2014) 8(6):5585-99. doi: 10.1021/nn406454u

93. Gao DN, Yang ZX, Qi QH. Roles of PD-1, Tim-3 and CTLA-4 in Immunoregulation in Regulatory $\mathrm{T}$ Cells Among Patients With Sepsis. Int J Clin Exp Med (2015) 8(10):18998-9005.

94. Willers M, Ulas T, Vollger L, Vogl T, Heinemann AS, Pirr S, et al. S100A8 and S100A9 Are Important for Postnatal Development of Gut Microbiota and Immune System in Mice and Infants. Gastroenterology (2020) 159 (6):2130-45 e5. doi: 10.1053/j.gastro.2020.08.019

95. Sun Y, Xie J, Anyalebechi JC, Chen CW, Sun H, Xue M, et al. CD28 Agonism Improves Survival in Immunologically Experienced Septic Mice via IL-10 Released by Foxp3(+) Regulatory T Cells. J Immunol (2020) 205(12):335871. doi: 10.4049/jimmunol.2000595

96. Ge Y, Huang M, Wu Y, Dong N, Yao YM. Interleukin-38 Protects Against Sepsis by Augmenting Immunosuppressive Activity of CD4(+) CD25(+) Regulatory T Cells. J Cell Mol Med (2020) 24(2):2027-39. doi: 10.1111/ jcmm.14902
97. Kulkarni U, Herrmenau C, Win SJ, Bauer M, Kamradt T. IL-7 Treatment Augments and Prolongs Sepsis-Induced Expansion of IL-10-Producing B Lymphocytes and Myeloid-Derived Suppressor Cells. PloS One (2018) 13(2): e0192304. doi: 10.1371/journal.pone.0192304

98. Nadeem A, Al-Harbi NO, Ahmad SF, Al-Harbi MM, Alhamed AS, Alfardan AS, et al. Blockade of Interleukin-2-Inducible T-Cell Kinase Signaling Attenuates Acute Lung Injury in Mice Through Adjustment of Pulmonary Th17/Treg Immune Responses and Reduction of Oxidative Stress. Int Immunopharmacol (2020) 83:106369. doi: 10.1016/j.intimp.2020.106369

99. Li H, Qiu D, Yang H, Yuan Y, Wu L, Chu L, et al. Therapeutic Efficacy of Excretory-Secretory Products of Trichinella Spiralis Adult Worms on SepsisInduced Acute Lung Injury in a Mouse Model. Front Cell Infect Microbiol (2021) 11:653843. doi: 10.3389/fcimb.2021.653843

100. Liu J, Li G, Chen YZ, Zhang LD, Wang T, Wen ZL, et al. Effects of Rhubarb on the Expression of Glucocorticoids Receptor and Regulation of Cellular Immunity in Burn-Induced Septic Rats. Chin Med J (Engl) (2019) 132 (10):1188-93. doi: 10.1097/CM9.0000000000000201

101. Ge Y, Huang M, Dong N, Yao YM. Effect of Interleukin-36beta on Activating Autophagy of CD4+CD25+ Regulatory T Cells and Its Immune Regulation in Sepsis. J Infect Dis (2020) 222(9):1517-30. doi: 10.1093/infdis/jiaa258

102. Brichacek AL, Benkovic SA, Chakraborty S, Nwafor DC, Wang W, Jun S, et al. Systemic Inhibition of Tissue-Nonspecific Alkaline Phosphatase Alters the Brain-Immune Axis in Experimental Sepsis. Sci Rep (2019) 9(1):18788. doi: 10.1038/s41598-019-55154-2

103. Gao M, Ou H, Jiang Y, Wang K, Peng Y, Zhang H, et al. Tanshinone IIA Attenuates Sepsis-Induced Immunosuppression and Improves Survival Rate in a Mice Peritonitis Model. BioMed Pharmacother (2019) 112:108609. doi: 10.1016/j.biopha.2019.108609

104. Chen X, Feng Y, Shen X, Pan G, Fan G, Gao X, et al. Anti-Sepsis Protection of Xuebijing Injection is Mediated by Differential Regulation of Pro- and AntiInflammatory Th17 and T Regulatory Cells in a Murine Model of Polymicrobial Sepsis. J Ethnopharmacol (2018) 211:358-65. doi: 10.1016/ j.jep.2017.10.001

105. Chen L, Lu Y, Zhao L, Hu L, Qiu Q, Zhang Z, et al. Curcumin Attenuates Sepsis-Induced Acute Organ Dysfunction by Preventing Inflammation and Enhancing the Suppressive Function of Tregs. Int Immunopharmacol (2018) 61:1-7. doi: 10.1016/j.intimp.2018.04.041

106. Xie DP, Zhou GB, Chen RL, Qin XL, Du JD, Zhang Y, et al. Effect of Electroacupuncture at Zusanli (ST36) on Sepsis Induced by Cecal Ligation Puncture and Its Relevance to Spleen. Evid Based Complement Alternat Med (2020) 2020:1914031. doi: 10.1155/2020/1914031

107. Hou YC, Wu JM, Chen KY, Chen PD, Lei CS, Yeh SL, et al. Effects of Prophylactic Administration of Glutamine on CD4(+) T Cell Polarisation and Kidney Injury in Mice With Polymicrobial Sepsis. Br J Nutr (2019) 122 (6):657-65. doi: 10.1017/S0007114519000990

108. Yeh CL, Tanuseputero SA, Wu JM, Tseng YR, Yang PJ, Lee PC, et al. Intravenous Arginine Administration Benefits CD4(+) T-Cell Homeostasis and Attenuates Liver Inflammation in Mice With Polymicrobial Sepsis. Nutrients (2020) 12(4):1047. doi: 10.3390/nu12041047

109. Di Caro V, Cummings JL, Alcamo AM, Piganelli JD, Clark RSB, Morowitz MJ, et al. Dietary Cellulose Supplementation Modulates the Immune Response in a Murine Endotoxemia Model. Shock (2019) 51(4):526-34. doi: 10.1097/SHK.0000000000001180

110. Yamaguchi $M$, Hirose $Y$, Takemura $M$, Ono $M$, Sumitomo T, Nakata $M$, et al. Streptococcus Pneumoniae Evades Host Cell Phagocytosis and Limits Host Mortality Through Its Cell Wall Anchoring Protein PfbA. Front Cell Infect Microbiol (2019) 9:301. doi: 10.3389/fcimb.2019.00301

111. Albayati S, Vemulapalli H, Tsygankov AY, Liverani E. P2Y12 Antagonism Results in Altered Interactions Between Platelets and Regulatory T Cells During Sepsis. J Leukoc Biol (2020) 110(1):141-53. doi: 10.1002/JLB.3A0220097R

112. Guo Y, Wu B, Chen Q, Min S. Parecoxib Ameliorates Renal Toxicity and Injury in Sepsis-Induced Mouse Model and LPS-Induced HK-2 Cells. Drug Dev Res (2021) 10.1002/ddr.21897. doi: 10.1002/ddr.21897

113. Ahmad A, Vieira JC, de Mello AH, de Lima TM, Ariga SK, Barbeiro DF, et al. The PARP Inhibitor Olaparib Exerts Beneficial Effects in Mice Subjected to Cecal Ligature and Puncture and in Cells Subjected to Oxidative Stress Without Impairing DNA Integrity: A Potential Opportunity for Repurposing 
a Clinically Used Oncological Drug for the Experimental Therapy of Sepsis. Pharmacol Res (2019) 145:104263. doi: 10.1016/j.phrs.2019.104263

114. Cao C, Yin C, Chai Y, Jin H, Wang L, Shou S. Ulinastatin Mediates Suppression of Regulatory T Cells Through TLR4/NF-kappaB Signaling Pathway in Murine Sepsis. Int Immunopharmacol (2018) 64:411-23. doi: 10.1016/j.intimp.2018.09.025

115. Topcu Sarica L, Zibandeh N, Genc D, Gul F, Akkoc T, Kombak EF, et al. Immunomodulatory and Tissue-Preserving Effects of Human Dental Follicle Stem Cells in a Rat Cecal Ligation and Perforation Sepsis Model. Arch Med Res (2020) 51(5):397-405. doi: 10.1016/j.arcmed.2020.04.010

116. Chang CL, Chen HH, Chen KH, Chiang JY, Li YC, Lin HS, et al. AdiposeDerived Mesenchymal Stem Cell-Derived Exosomes Markedly Protected the Brain Against Sepsis Syndrome Induced Injury in Rat. Am J Transl Res (2019) 11(7):3955-71.

117. Zhang L, Zhang JP, Liu Y, Wang H, Cheng Y, Wang JH, et al. Plasma Transfusion Promoted Reprogramming CD4(+) T Lymphocytes Immune Response in Severe Sepsis Mice Model Through Modulating the Exosome Protein Galectin 9. Cell Transplant (2020) 29:963689720947347. doi: $10.1177 / 0963689720947347$

118. Kyvelidou C, Sotiriou D, Zerva I, Athanassakis I. Protection Against Lipopolysaccharide-Induced Immunosuppression by IgG and IgM. Shock (2018) 49(4):474-82. doi: 10.1097/SHK.0000000000000937

119. Chihara S, Masuda Y, Tatsumi H, Yamakage M. Evaluation of Pre- and PostDilution Continuous Veno-Venous Hemofiltration on Leukocyte and Platelet Function in Patients With Sepsis. Int J Artif Organs (2019) 42 (1):9-16. doi: 10.1177/0391398818801292

120. Qi X, Yu Y, Sun R, Huang J, Liu L, Yang Y, et al. Identification and Characterization of Neutrophil Heterogeneity in Sepsis. Crit Care (2021) 25 (1):50. doi: 10.1186/s13054-021-03481-0

121. Martin MD, Badovinac VP, Griffith TS. CD4 T Cell Responses and the Sepsis-Induced Immunoparalysis State. Front Immunol (2020) 11:1364. doi: 10.3389/fimmu.2020.01364

122. Monneret G, Debard AL, Venet F, Bohe J, Hequet O, Bienvenu J, et al. Marked Elevation of Human Circulating CD4+CD25+ Regulatory T Cells in Sepsis-Induced Immunoparalysis. Crit Care Med (2003) 31(7):2068-71. doi: 10.1097/01.CCM.0000069345.78884.0F

123. Venet F, Chung CS, Kherouf H, Geeraert A, Malcus C, Poitevin F, et al. Increased Circulating Regulatory T Cells (CD4(+)CD25 (+)CD127 (-)) Contribute to Lymphocyte Anergy in Septic Shock Patients. Intensive Care Med (2009) 35(4):678-86. doi: 10.1007/s00134-008-1337-8

124. Venet F, Pachot A, Debard AL, Bohe J, Bienvenu J, Lepape A, et al. Human CD4+CD25+ Regulatory T Lymphocytes Inhibit LipopolysaccharideInduced Monocyte Survival Through a Fas/Fas Ligand-Dependent Mechanism. J Immunol (2006) 177(9):6540-7. doi: 10.4049/ jimmunol.177.9.6540

125. Huang LF, Yao YM, Dong N, Yu Y, He LX, Sheng ZY. Association Between Regulatory T Cell Activity and Sepsis and Outcome of Severely Burned Patients: A Prospective, Observational Study. Crit Care (2010) 14(1):R3. doi: $10.1186 / \mathrm{cc} 8232$

126. Tao L, Wang Y, Xu J, Su J, Yang Q, Deng W, et al. IL-10-Producing Regulatory B Cells Exhibit Functional Defects and Play a Protective Role in Severe Endotoxic Shock. Pharmacol Res (2019) 148:104457. doi: 10.1016/ j.phrs.2019.104457

127. Cagdas D, Halaçlı SO, Tan Ç, Lo B, Çetinkaya PG, Esenboğa S, et al. A Spectrum of Clinical Findings From ALPS to CVID: Several Novel LRBA Defects. J Clin Immunol (2019) 39(7):726-38. doi: 10.1007/s10875-01900677-6

128. Halliday N, Williams C, Kennedy A, Waters E, Pesenacker AM, Soskic B, et al. CD86 Is a Selective CD28 Ligand Supporting FoxP3+ Regulatory T Cell Homeostasis in the Presence of High Levels of CTLA-4. Front Immunol (2020) 11:600000. doi: 10.3389/fimmu.2020.600000

129. Mack DG, Lanham AM, Palmer BE, Maier LA, Fontenot AP. CD27 Expression on CD4+ T Cells Differentiates Effector From Regulatory $\mathrm{T}$ Cell Subsets in the Lung. J Immunol (2009) 182(11):7317-24. doi: 10.4049/ jimmunol.0804305

130. Hippen KL, Harker-Murray P, Porter SB, Merkel SC, Londer A, Taylor DK, et al. Umbilical Cord Blood Regulatory T-Cell Expansion and Functional Effects of Tumor Necrosis Factor Receptor Family Members OX40 and 4-
1BB Expressed on Artificial Antigen-Presenting Cells. Blood (2008) 112 (7):2847-57. doi: 10.1182/blood-2008-01-132951

131. Lucca LE, Dominguez-Villar M. Modulation of Regulatory T Cell Function and Stability by Co-Inhibitory Receptors. Nat Rev Immunol (2020) 20 (11):680-93. doi: 10.1038/s41577-020-0296-3

132. Polanczyk MJ, Hopke C, Vandenbark AA, Offner H. Treg Suppressive Activity Involves Estrogen-Dependent Expression of Programmed Death-1 (PD-1). Int Immunol (2007) 19(3):337-43. doi: 10.1093/intimm/dxl151

133. Hwang WC, Seo SH, Kang M, Kang RH, Di Paolo G, Choi KY, et al. PLD1 and PLD2 Differentially Regulate the Balance of Macrophage Polarization in Inflammation and Tissue Injury. J Cell Physiol (2021) 236(7):5193-211. doi: $10.1002 /$ jcp.30224

134. Yu K, Dong Q, Mao X, Meng K, Zhao X, Ji Q, et al. Disruption of the TSLPTSLPR-LAP Signaling Between Epithelial and Dendritic Cells Through Hyperlipidemia Contributes to Regulatory T-Cell Defects in Atherosclerotic Mice. Atherosclerosis (2015) 238(2):278-88. doi: 10.1016/ j.atherosclerosis.2014.12.019

135. Seymour CW, Kennedy JN, Wang S, Chang CH, Elliott CF, Xu Z, et al. Derivation, Validation, and Potential Treatment Implications of Novel Clinical Phenotypes for Sepsis. JAMA (2019) 321(20):2003-17. doi: 10.1001/jama.2019.5791

136. Stortz JA, Cox MC, Hawkins RB, Ghita GL, Brumback BA, Mohr AM, et al. Phenotypic Heterogeneity by Site of Infection in Surgical Sepsis: A Prospective Longitudinal Study. Crit Care (2020) 24(1):203. doi: 10.1186/ s13054-020-02917-3

137. Markwart R, Saito H, Harder T, Tomczyk S, Cassini A, Fleischmann-Struzek C, et al. Epidemiology and Burden of Sepsis Acquired in Hospitals and Intensive Care Units: A Systematic Review and Meta-Analysis. Intensive Care Med (2020) 46(8):1536-51. doi: 10.1007/s00134-020-06106-2

138. Greenberg JA, Hrusch CL, Jaffery MR, David MZ, Daum RS, Hall JB, et al. Distinct T-Helper Cell Responses to Staphylococcus Aureus Bacteremia Reflect Immunologic Comorbidities and Correlate With Mortality. Crit Care (2018) 22(1):107. doi: 10.1186/s13054-018-2025-x

139. Gea-Banacloche JC, Opal SM, Jorgensen J, Carcillo JA, Sepkowitz KA, Cordonnier C. Sepsis Associated With Immunosuppressive Medications: An Evidence-Based Review. Crit Care Med (2004) 32(11 Suppl):S578-90. doi: 10.1097/01.CCM.0000143020.27340.FF

140. Kamboj M, Sepkowitz KA. Nosocomial Infections in Patients With Cancer. Lancet Oncol (2009) 10(6):589-97. doi: 10.1016/S1470-2045(09)70069-5

141. Sheth M, Benedum CM, Celi LA, Mark RG, Markuzon N. The Association Between Autoimmune Disease and 30-Day Mortality Among Sepsis ICU Patients: A Cohort Study. Crit Care (2019) 23(1):93. doi: 10.1186/s13054019-2357-1

142. Zhao GJ, Li D, Zhao Q, Song JX, Chen XR, Hong GL, et al. Incidence, Risk Factors and Impact on Outcomes of Secondary Infection in Patients With Septic Shock: An 8-Year Retrospective Study. Sci Rep (2016) 6:38361. doi: 10.1038/srep38361

143. Yang XD, Kong FE, Qi L, Lin JX, Yan Q, Loong JHC, et al. PARP Inhibitor Olaparib Overcomes Sorafenib Resistance Through Reshaping the Pluripotent Transcriptome in Hepatocellular Carcinoma. Mol Cancer (2021) 20(1):20. doi: 10.1186/s12943-021-01315-9

144. Mukhopadhyay S, Puopolo KM, Hansen NI, Lorch SA, DeMauro SB, Greenberg RG, et al. Impact of Early-Onset Sepsis and Antibiotic Use on Death or Survival With Neurodevelopmental Impairment at 2 Years of Age Among Extremely Preterm Infants. J Pediatr (2020) 221:39-46 e5. doi: 10.1016/j.jpeds.2020.02.038

145. Polcwiartek LB, Smith PB, Benjamin DK, Zimmerman K, Love A, Tiu L, et al. Early-Onset Sepsis in Term Infants Admitted to Neonatal Intensive Care Units (2011-2016). J Perinatol (2021) 41(1):157-63. doi: 10.1038/s41372020-00860-3

146. Youssef MAM, Zahran AM, Hussien AM, Elsayh KI, Askar EA, Farghaly HS. In Neonates With Vitamin D Deficiency, Low Lymphocyte Activation Markers are Risk Factors for Infection. Paediatr Int Child Health (2019) 39(2):111-8. doi: 10.1080/20469047.2018.1528755

147. Saito K, Wagatsuma T, Toyama H, Ejima Y, Hoshi K, Shibusawa M, et al. Sepsis is Characterized by the Increases in Percentages of Circulating CD4 +CD25+ Regulatory T Cells and Plasma Levels of Soluble CD25. Tohoku J Exp Med (2008) 216(1):61-8. doi: 10.1620/tjem.216.61 
148. Cho DS, Schmitt RE, Dasgupta A, Ducharme AM, Doles JD. Single-Cell Deconstruction of Post-Sepsis Skeletal Muscle and Adipose Tissue Microenvironments. J Cachexia Sarcopenia Muscle (2020) 11(5):1351-63. doi: $10.1002 / j \mathrm{csm} .12596$

149. Aird WC. Phenotypic Heterogeneity of the Endothelium: I. Structure, Function, and Mechanisms. Circ Res (2007) 100(2):158-73. doi: 10.1161/ 01.RES.0000255691.76142.4a

150. Toledo AG, Golden G, Campos AR, Cuello H, Sorrentino J, Lewis N, et al. Proteomic Atlas of Organ Vasculopathies Triggered by Staphylococcus Aureus Sepsis. Nat Commun (2019) 10(1):4656. doi: 10.1038/s41467-019-12672-x

151. Margraf A, Ley K, Zarbock A. Neutrophil Recruitment: From Model Systems to Tissue-Specific Patterns. Trends Immunol (2019) 40(7):613-34. doi: 10.1016/j.it.2019.04.010

152. Barrot L, Asfar P, Mauny F, Winiszewski H, Montini F, Badie J, et al. Liberal or Conservative Oxygen Therapy for Acute Respiratory Distress Syndrome. N Engl J Med (2020) 382(11):999-1008. doi: 10.1056/NEJMoa1916431

153. Thompson BT, Chambers RC, Liu KD. Acute Respiratory Distress Syndrome. N Engl J Med (2017) 377(6):562-72. doi: 10.1056/NEJMra1608077

154. Ranieri VM, Pettila V, Karvonen MK, Jalkanen J, Nightingale P, Brealey D, et al. Effect of Intravenous Interferon Beta-1a on Death and Days Free From Mechanical Ventilation Among Patients With Moderate to Severe Acute Respiratory Distress Syndrome: A Randomized Clinical Trial. JAMA (2020) 323(8):725-33. doi: 10.1001/jama.2019.22525

155. D'Alessio FR, Tsushima K, Aggarwal NR, West EE, Willett MH, Britos MF, et al. CD4+CD25+Foxp3+ Tregs Resolve Experimental Lung Injury in Mice and are Present in Humans With Acute Lung Injury. J Clin Invest (2009) 119 (10):2898-913. doi: 10.1172/JCI36498

156. Chung HY, Wickel J, Brunkhorst FM, Geis C. Sepsis-Associated Encephalopathy: From Delirium to Dementia? J Clin Med (2020) 9(3):703. doi: $10.3390 / \mathrm{jcm} 9030703$

157. Sonneville R, de Montmollin E, Poujade J, Garrouste-Orgeas M, Souweine B, Darmon M, et al. Potentially Modifiable Factors Contributing to SepsisAssociated Encephalopathy. Intensive Care Med (2017) 43(8):1075-84. doi: $10.1007 / \mathrm{s} 00134-017-4807-\mathrm{z}$

158. Ren C, Yao RQ, Zhang H, Feng YW, Yao YM. Sepsis-Associated Encephalopathy: A Vicious Cycle of Immunosuppression. J Neuroinflamm (2020) 17(1):14. doi: 10.1186/s12974-020-1701-3

159. Iwashyna TJ, Ely EW, Smith DM, Langa KM. Long-Term Cognitive Impairment and Functional Disability Among Survivors of Severe Sepsis. JAMA (2010) 304(16):1787-94. doi: 10.1001/jama.2010.1553

160. Wintermann GB, Brunkhorst FM, Petrowski K, Strauss B, Oehmichen F, Pohl M, et al. Stress Disorders Following Prolonged Critical Illness in Survivors of Severe Sepsis. Crit Care Med (2015) 43(6):1213-22. doi: 10.1097/CCM.0000000000000936

161. Dejager L, Pinheiro I, Dejonckheere E, Libert C. Cecal Ligation and Puncture: The Gold Standard Model for Polymicrobial Sepsis? Trends Microbiol (2011) 19(4):198-208. doi: 10.1016/j.tim.2011.01.001

162. Brinkhoff A, Sieberichs A, Engler H, Dolff S, Benson S, Korth J, et al. ProInflammatory Th1 and Th17 Cells Are Suppressed During Human Experimental Endotoxemia Whereas Anti-Inflammatory IL-10 Producing T-Cells Are Unaffected. Front Immunol (2018) 9:1133. doi: 10.3389/fimmu.2018.01133

163. Kinjo Y, Illarionov P, Vela JL, Pei B, Girardi E, Li X, et al. Invariant Natural Killer T Cells Recognize Glycolipids From Pathogenic Gram-Positive Bacteria. Nat Immunol (2011) 12(10):966-74. doi: 10.1038/ni.2096

164. Venken K, Decruy T, Aspeslagh S, Van Calenbergh S, Lambrecht BN, Elewaut D. Bacterial CD1d-Restricted Glycolipids Induce IL-10 Production by Human Regulatory T Cells Upon Cross-Talk With Invariant NKT Cells. J Immunol (2013) 191(5):2174-83. doi: 10.4049/jimmunol.1300562

165. Kim BG, Ghosh P, Ahn S, Rhee DK. Pneumococcal Pep27 Mutant Immunization Suppresses Allergic Asthma in Mice. Biochem Biophys Res Commun (2019) 514(1):210-6. doi: 10.1016/j.bbrc.2019.04.116

166. Lee SW, Park HJ, Van Kaer L, Hong S, Hong S. Graphene Oxide Polarizes iNKT Cells for Production of TGFbeta and Attenuates Inflammation in an iNKT Cell-Mediated Sepsis Model. Sci Rep (2018) 8(1):10081. doi: 10.1038/ s41598-018-28396-9

167. Qu G, Liu S, Zhang S, Wang L, Wang X, Sun B, et al. Graphene Oxide Induces Toll-Like Receptor 4 (TLR4)-Dependent Necrosis in Macrophages. ACS Nano (2013) 7(7):5732-45. doi: 10.1021/nn402330b
168. Schuijt TJ, Lankelma JM, Scicluna BP, de Sousa e Melo F, Roelofs JJ, de Boer JD, et al. The Gut Microbiota Plays a Protective Role in the Host Defence Against Pneumococcal Pneumonia. Gut (2016) 65(4):575-83. doi: 10.1136/ gutjnl-2015-309728

169. Morowitz MJ, Di Caro V, Pang D, Cummings J, Firek B, Rogers MB, et al. Dietary Supplementation With Nonfermentable Fiber Alters the Gut Microbiota and Confers Protection in Murine Models of Sepsis. Crit Care Med (2017) 45(5):e516-e23. doi: 10.1097/CCM.0000000000002291

170. Boeddha NP, Schlapbach LJ, Driessen GJ, Herberg JA, Rivero-Calle I, CebeyLopez M, et al. Mortality and Morbidity in Community-Acquired Sepsis in European Pediatric Intensive Care Units: A Prospective Cohort Study From the European Childhood Life-Threatening Infectious Disease Study (EUCLIDS). Crit Care (2018) 22(1):143. doi: 10.1186/s13054-018-2052-7

171. Vincent JL, Sakr Y, Sprung CL, Ranieri VM, Reinhart K, Gerlach H, et al. Sepsis in European Intensive Care Units: Results of the SOAP Study. Crit Care Med (2006) 34(2):344-53. doi: 10.1097/01.CCM.0000194725.48928.3A

172. Netea MG, Sutmuller R, Hermann C, van der Graaf CA, van der Meer JW, van Krieken JH, et al. Toll-Like Receptor 2 Suppresses Immunity Against Candida Albicans Through Induction of IL-10 and Regulatory T Cells. $J$ Immunol (2004) 172(6):3712-8. doi: 10.4049/jimmunol.172.6.3712

173. Arens C, Kramm T, Decker S, Spannenberger J, Brenner T, Richter DC, et al. Association of Immune Cell Subtypes and Phenotype With Subsequent Invasive Candidiasis in Patients With Abdominal Sepsis. Shock (2019) 52 (2):191-7. doi: 10.1097/SHK.0000000000001251

174. Kuhlhorn F, Rath M, Schmoeckel K, Cziupka K, Nguyen HH, Hildebrandt P, et al. Foxp3+ Regulatory T Cells are Required for Recovery From Severe Sepsis. PloS One (2013) 8(5):e65109. doi: 10.1371/journal.pone.0065109

175. Alverdy JC, Keskey R, Thewissen R. Can the Cecal Ligation and Puncture Model Be Repurposed To Better Inform Therapy in Human Sepsis? Infect Immun (2020) 88(9):e00942-19. doi: 10.1128/IAI.00942-19

176. Barber AE, Coyle SM, Fischer E, Smith C, van der Poll T, Shires GT, et al. Influence of Hypercortisolemia on Soluble Tumor Necrosis Factor Receptor II and Interleukin-1 Receptor Antagonist Responses to Endotoxin in Human Beings. Surgery (1995) 118(2):406-10. doi: 10.1016/s0039-6060(05)80352-6

177. Thomas RC, Bath MF, Stover CM, Lambert DG, Thompson JP. Exploring LPS-Induced Sepsis in Rats and Mice as a Model to Study Potential Protective Effects of the Nociceptin/Orphanin FQ System. Peptides (2014) 61:56-60. doi: 10.1016/j.peptides.2014.08.009

178. Spenlingwimmer T, Zipperle J, Jafarmadar M, Osuchowski MF, Drechsler S. Comparison of Post-Traumatic Changes in Circulating and Bone Marrow Leukocytes Between BALB/c and CD-1 Mouse Strains. PloS One (2019) 14 (9):e0222594. doi: 10.1371/journal.pone.0222594

179. Harb H, Benamar M, Lai PS, Contini P, Griffith JW, Crestani E. Notch4 Signaling Limits Regulatory T-Cell-Mediated Tissue Repair and Promotes Severe Lung Inflammation in Viral Infections. Immunity (2021) 54(6):118699.e7. doi: 10.1016/j.immuni.2021.04.002

180. D'Alessio FR, Tsushima K, Aggarwal NR, West EE, Willett MH, Britos MF. CD4+CD25+Foxp3+ Tregs Resolve Experimental Lung Injury in Mice and Are Present in Humans With Acute Lung Injury. J Clin Invest (2009) 119 (10):2898-913. doi: 10.1172/JCI36498

181. Mock JR, Garibaldi BT, Aggarwal NR, Jenkins J, Limjunyawong N, Singer BD. Foxp3+ Regulatory T Cells Promote Lung Epithelial Proliferation. Mucosal Immunol (2014) 7(6):1440-51. doi: 10.1038/mi.2014.33

182. Yu ZX, Ji MS, Yan J, Cai Y, Liu J, Yang HF. The Ratio of Th17/Treg Cells as a Risk Indicator in Early Acute Respiratory Distress Syndrome. Crit Care (2015) 19(1):82. doi: 10.1186/s13054-015-0811-2

183. Zhang F, Li MY, Lan YT, Wang CB. Imbalance of Th17/Tregs in Rats With Smoke Inhalation-Induced Acute Lung Injury. Sci Rep (2016) 6:21348. doi: 10.1038/srep21348

184. Chen G, Wu MD, Guo W, Cao Y, Huang D, Wang H. Clinical and Immunological Features of Severe and Moderate Coronavirus Disease 2019. J Clin Invest (2020) 130(5):2620-9.

185. Wang F, Hou H, Luo Y, Tang G, Wu S, Huang M. The Laboratory Tests and Host Immunity of COVID-19 Patients With Different Severity of Illness. JCI Insight (2020) 5(10):e137799.

186. Tan M, Liu Y, Zhou R, Deng X, Li F, Liang K. Immunopathological Characteristics of Coronavirus Disease 2019 Cases in Guangzhou, China. Immunology (2020) 160(3):261-8. 
187. Neumann J, Prezzemolo T, Vanderbeke L, Roca CP, Gerbaux M, Janssens S. Increased IL-10-Producing Regulatory T Cells Are Characteristic of Severe Cases of COVID-19. Clin Transl Immunol (2020) 9(11):e1204.

188. Meckiff BJ, Ramírez-Suástegui C, Fajardo V, Chee SJ, Kusnadi A, Simon H. Imbalance of Regulatory and Cytotoxic SARS-CoV-2-Reactive CD4+ T Cells in COVID-19. Cell (2020) 183(5):1340-53.e16. doi: 10.1016/j.cell.2020.10.001

Conflict of Interest: XT was employed by Beijing Qiansong Technology Development Company.

The remaining authors declare that the research was conducted in the absence of any commercial or financial relationships that could be construed as a potential conflict of interest.
Publisher's Note: All claims expressed in this article are solely those of the authors and do not necessarily represent those of their affiliated organizations, or those of the publisher, the editors and the reviewers. Any product that may be evaluated in this article, or claim that may be made by its manufacturer, is not guaranteed or endorsed by the publisher.

Copyright $\odot 2022$ Gao, Yao, Zhang, Chen, Meng, Chen, Wang, Liu, Tian, Shou and Chai. This is an open-access article distributed under the terms of the Creative Commons Attribution License (CC BY). The use, distribution or reproduction in other forums is permitted, provided the original author(s) and the copyright owner(s) are credited and that the original publication in this journal is cited, in accordance with accepted academic practice. No use, distribution or reproduction is permitted which does not comply with these terms. 